\title{
Hydrogenative Metathesis of Enynes via Piano-Stool Ruthenium Carbene Complexes Formed by Alkyne gem-Hydrogenation
}

\author{
Sebastian Peil, Giovanni Bistoni, Richard Goddard, and Alois Fürstner* \\ Cite This: J. Am. Chem. Soc. 2020, 142, 18541-18553 \\ Read Online
}

ABSTRACT: The only recently discovered gem-hydrogenation of internal alkynes is a fundamentally new transformation, in which both $\mathrm{H}$ atoms of dihydrogen are transferred to the same $\mathrm{C}$ atom of a triple bond while the other position transforms into a discrete metal carbene complex. $[\mathrm{Cp} * \mathrm{RuCl}]_{4}$ is presently the catalyst of choice: the resulting piano-stool ruthenium carbenes can engage a tethered alkene into either cyclopropanation or metathesis, and a prototypical example of such a reactive intermediate with an olefin ligated to the ruthenium center has been isolated and characterized by X-ray diffraction. It is the substitution pattern of the olefin that determines whether metathesis or cyclopropanation takes place: a systematic survey using alkenes of largely

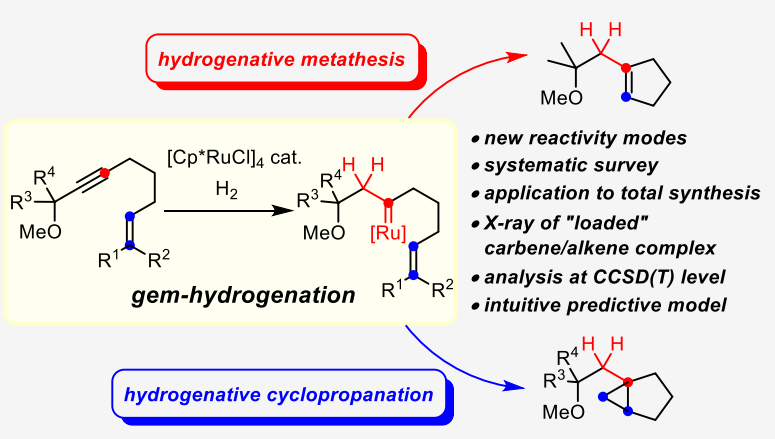
different character in combination with a computational study of the mechanism at the local coupled cluster level of theory allowed the preparative results to be sorted and an intuitive model with predictive power to be proposed. This model links the course of the reaction to the polarization of the double bond as well as to the stability of the secondary carbene complex formed, if metathesis were to take place. The first application of "hydrogenative metathesis" to the total synthesis of sinularones E and F concurred with this interpretation and allowed the proposed structure of these marine natural products to be confirmed. During this synthesis, it was found that gem-hydrogenation also provides opportunities for $\mathrm{C}-\mathrm{H}$ functionalization. Moreover, silylated alkynes are shown to participate well in hydrogenative metathesis, which opens a new entry into valuable allylsilane building blocks. Crystallographic evidence suggests that the polarized [Ru-Cl] bond of the catalyst interacts with the neighboring $\mathrm{R}_{3} \mathrm{Si}$ group. Since attractive interligand $\mathrm{Cl} / \mathrm{R}_{3} \mathrm{Si}$ contacts had already previously been invoked to explain the outcome of various ruthenium-catalyzed reactions, including trans-hydrosilylation, the experimental confirmation provided herein has implications beyond the present case.

\section{INTRODUCTION}

The catalytic gem-hydrogenation of internal alkynes is a fundamentally new reactivity mode: it allows both $\mathrm{H}$ atoms of dihydrogen to be transferred to the same $\mathrm{C}$ atom of a triple bond, whereas the second $\mathrm{C}$ atom is concomitantly transformed into a discrete metal carbene. ${ }^{1}$ This unprecedented outcome was originally discovered during mechanistic studies into the equally perplexing trans-hydrogenation of alkynes with the aid of $[\mathrm{Cp} * \mathrm{Ru}]$-based catalysts (Scheme 1$).^{2-4}$

The reaction commences with the upload of the substrate and $\mathrm{H}_{2}$ onto the ruthenium catalyst as shown in $\mathbf{A}$, followed by a first hydrogen transfer to the $\pi$ system activated by the carbophilic metal fragment. ${ }^{5}$ If the second $\mathrm{H}$ atom is delivered to the $\mathrm{C}_{\alpha}$ position, the resulting ruthenacyclopropene $\mathbf{B}^{6}$ evolves in a concerted manner into complex $\mathbf{E}$, from which the E-olefin $\mathbf{F}$ is released. Competing transfer to $\mathrm{C}_{\beta}$, however, constitutes the actual "gem-hydrogenation" event: the resulting piano-stool ruthenium carbene $\mathbf{C}$ flanked by the newly formed methylene group can also transform into alkene $\mathbf{F}$, provided that a second molecule of $\mathrm{H}_{2}$ binds to the metal center to lower the barriers. For an unbiased substrate such as 2-butyne, the two interwoven pathways were computed to have basically the same probability; ${ }^{2,3}$ polarization of the triple bond and/or incorporation of a propargylic substituent able to ligate the $\mathrm{Ru}$ center tips the scales such that gem-hydrogenation becomes the dominant or even exclusive course. ${ }^{2,3}$ Moreover, a distinct correlation between the electronic properties of the ancillary $\mathrm{Cp}{ }^{\mathrm{X}}$ ligand and the ease of gem-hydrogenation was established. $^{7}$

Details apart, the generation of discrete metal carbene complexes via gem-hydrogenation of an alkyne provides an attractive outlook: ${ }^{1}$ if one is able to either block or outcompete the steps downstream of $\mathbf{C}$ that lead to the E-alkene $\mathbf{F}$, this process might be diverted and genuine carbene chemistry might be harnessed (Scheme 1). To this end, we pursued different lines of research and were able to achieve a proof of

Received: July 20, 2020

Published: October 19, 2020 
Scheme 1. Link between trans-Hydrogenation and gemHydrogenation $^{a}$

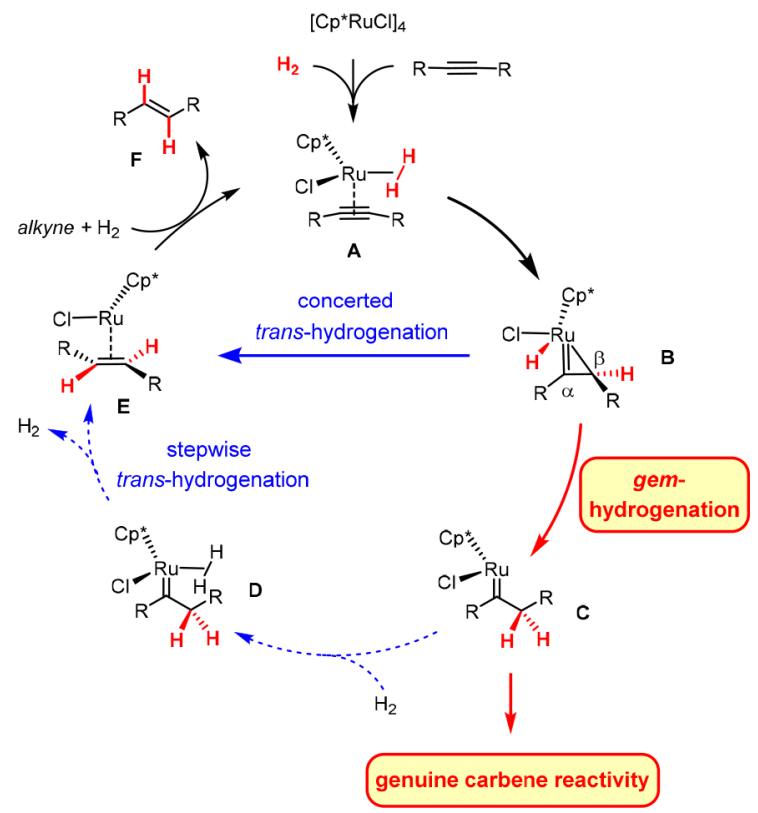

${ }^{a}$ The steps of the trans-hydrogenation pathway downstream of $\mathbf{C}$ that need to be blocked or outperformed in order to harness genuine carbene chemistry are shown as dotted arrows.

concept in more than one format: novel hydrogenative skeletal rearrangements, ${ }^{3}$ hydrogenative heterocycle syntheses, ${ }^{3,8}$ counterintuitive "hydrogenative cyclopropanation" reactions, $3,9,10$ and even a "hydrogenative metathesis" manifold have been discovered. ., $^{11}$ The present report is focused on this last transformation, which converts an enyne into a cycloalkene rather than into a 1,3-diene as conventional enyne metathesis would. ${ }^{12,13}$ Therefore, it embodies a new paradigm in metathesis. A combined experimental and computational approach provided insights into the factors controlling the reaction outcome and led to a refined mechanistic picture of this unorthodox transformation.

\section{RESULTS AND DISCUSSION}

Reaction Development. Cognizant of the need to steer gem-hydrogenation with the aid of a propargylic substituent, ${ }^{1-3}$ we initially chose enynes of type $\mathbf{1}$ as model substrates. As previously described, the outcome of the reaction is largely determined by the substitution of the olefinic site (Scheme $2):{ }^{9}$ while hydrogenation of $\mathbf{1 b}$ comprising a terminal alkene with $[\mathrm{Cp} * \mathrm{RuCl}]_{4}$ as a precatalyst in 1,2-dichloroethane at an elevated temperature furnished cyclopropane $\mathbf{3 b}$, its sibling $\mathbf{1 a}$ containing two methyl substituents on the alkene gave the metathesis product $\mathbf{2 a}$ under otherwise identical conditions. $^{14,15}$ This strikingly divergent behavior proved to be general $;{ }^{9}$ it came as a surprise in view of earlier literature reports which had found that putative carbene complexes of the type $\left[\mathrm{Cp} * \mathrm{Ru}(\mathrm{Cl})\left(=\mathrm{CR}_{2}\right)\right]$ generated in situ from diazo precursors are highly competent in cyclopropanation but essentially failed to effect olefin metathesis. ${ }^{16-21}$

These hydrogenative transformations work well as long as the propargylic substituent is a tertiary ether, silyl ether, or acetal, as illustrated by a range of diverse products (see ref 9 and the Supporting Information). For the time being, the reactions are limited to the formation of five- and six-
Scheme 2. Representative Example Showing the Effect of the Degree of Substitution on the Reaction Outcome

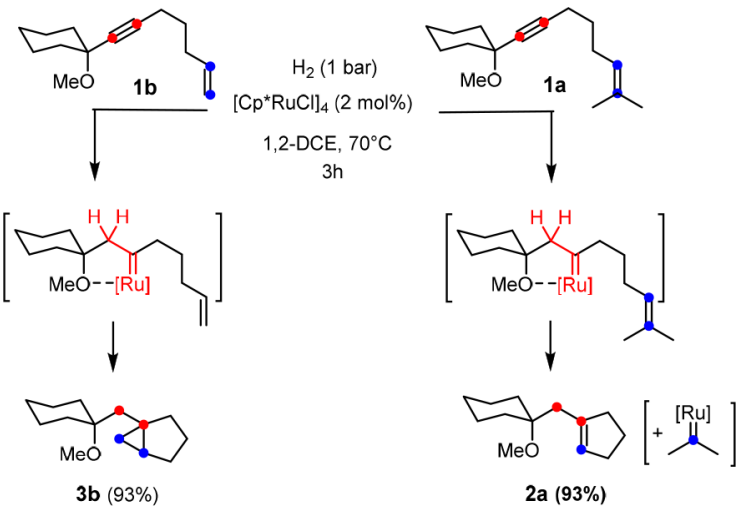

membered rings; all attempts at making larger cycles have so far met with failure likely because of the kinetic handicap in closing medium-sized or macrocyclic rings, which allows the competing trans-hydrogenation of the enyne via $\mathbf{C}$ and $\mathbf{D}$ (with/without over-reduction) to prevail. Moreover, the use of substrates containing (electron-rich) arenes, 1,3-dienes, or related motifs that bind more tightly to the $[\mathrm{Cp} * \mathrm{Ru}]$ fragment than to the triple bond to be gem-hydrogenated was usually met with failure; likewise, competing cycloisomerization was observed for certain enyne substrates (for representative examples, see the Supporting Information). ${ }^{22}$ On the other hand, it is noteworthy that all products formed by "hydrogenative metathesis" are trisubstituted olefins, which are not necessarily easy to make even with the aid of classical (firstgeneration) Grubbs-type catalysts; this is particularly true for trisubstituted butenolides or cyclic ketones such as 5-8, which posed significant challenges in the past but are well within the reach of this new methodology (Scheme 3). ${ }^{12,23,24}$

Scheme 3. Trisubstituted Cyclic Ketones and Butenolides Formed by "Hydrogenative Metathesis"

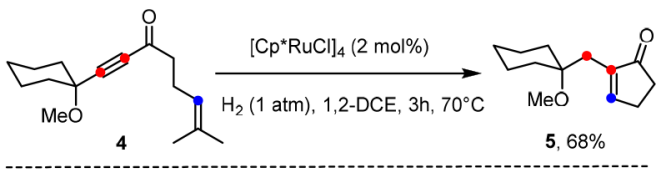

prepared analogously:
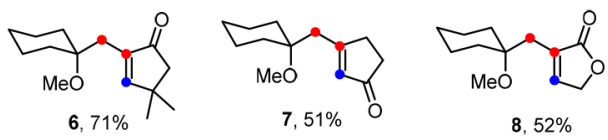

Total Synthesis of Sinularones E and F by Hydrogenative Metathesis. To assess this valuable aspect more closely, two unusual cyclopentenone derivatives isolated from a Sinularia octocoral collected off Hainan Island were chosen for a first application of the novel hydrogenative metathesis in the realm of natural product chemistry. ${ }^{25,26}$ The assignment of the relative stereochemistry of sinularones $\mathrm{E}$ and $\mathrm{F}$, which differ only in the configuration of $\mathrm{C} 7$, is solely based on computed ${ }^{13} \mathrm{C}$ NMR shifts and computed specific rotations and hence mandates experimental confirmation. From a synthetic viewpoint, these targets provide a rigorous testing ground for the new methodology because the gem-dimethyl group flanking the trisubstituted alkene to be metathesized entails notable steric 
hindrance (Scheme 4). Since hydrogenative metathesis requires a noncoordinating solvent, the presence of a cis-

Scheme 4. Structures and Retrosynthetic Analysis of Sinularones $\mathrm{E}$ and $\mathrm{F}$
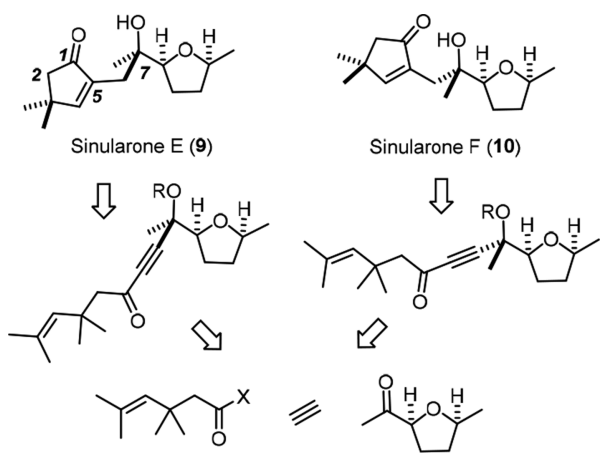

configured tetrahydrofuran moiety in the target compound was another point of concern, because it might entail the formation of an unfavorable six-membered chelate complex with the transient Lewis acidic carbene center. ${ }^{27}$

The required diastereomeric enyne substrates were readily attained starting from the cheap furan 11 (Scheme 5). On hydrogenation over $\mathrm{Rh} / \mathrm{Al}_{2} \mathrm{O}_{3}$, saturation of the aromatic ring precedes reduction of the ketone and hence allows the cisconfigured tetrahydrofuran $\mathbf{1 2}$ to be obtained on a gram scale, provided the reaction is properly monitored (see the Supporting Information). ${ }^{28,29}$ The subsequent addition of acetylide needed careful optimization because $\mathbf{1 2}$ is readily enolized on treatment with commercial $\mathrm{HC} \equiv \mathrm{CMgBr}$ at low temperature, leading to a complex mixture comprising the selfaldolization product 13 (mixture of isomers) as major constituent. The problem was remedied by the addition of $\mathrm{LaCl}_{3} \cdot 2 \mathrm{LiCl}$ to temper the basicity of the organometallic reagent. ${ }^{30,31}$ Under these conditions, the propargyl alcohols $\mathbf{1 4}$ were obtained in $74 \%$ combined yield $(66 \%$ on a $7.4 \mathrm{mmol}$ scale). As one might expect from a highly oxophilic Lewis acid, the major diastereomer 14a formed in the presence of $\mathrm{La}(3+)$ corresponds to the Cram-chelate adduct. ${ }^{32}$ The epimers 14a and $\mathbf{1 4} \mathbf{a}^{\prime}$ are readily separable, and both yielded single crystals suitable for X-ray diffraction (see the Supporting Information) $;^{33}$ as the corresponding carbinol center in sinularones $\mathrm{E}$ and $\mathrm{F}$ is the one that needs experimental proof, a sound basis for the completion of the total synthesis was reached.

In order to steer the projected carbene formation to the distal site of the triple bond of enyne $\mathbf{1 5}$ and hence ensure that the envisaged hydrogenative metathesis reaction proceeds with the desired regioselectivity, the tert-alcohol group must be protected. ${ }^{34}$ A priori, different silyl ethers or a SEM-acetal are adequate for this purpose and should be cleavable after the event under conditions that are sufficiently mild not to destroy the elimination-prone tert-alcohol in the resulting products. Therefore, compound 14a was transformed into $\mathbf{1 4 b - d}$ and these building blocks then coupled with Weinreb amide 18, which in turn is available from methyl vinyl ketone by following a literature route. ${ }^{35}$

With the three different enynes $\mathbf{1 5 b}-\mathbf{d}$ in hand, it was possible to test the hydrogenative metathesis as the key step of the synthesis. We were surprised to find that hydrogenation of the SEM derivative $\mathbf{1 5 b}$ under standard conditions using $[\mathrm{Cp} * \mathrm{RuCl}]_{4}$ as the catalyst furnished only trace amounts of the
Scheme $5^{a}$
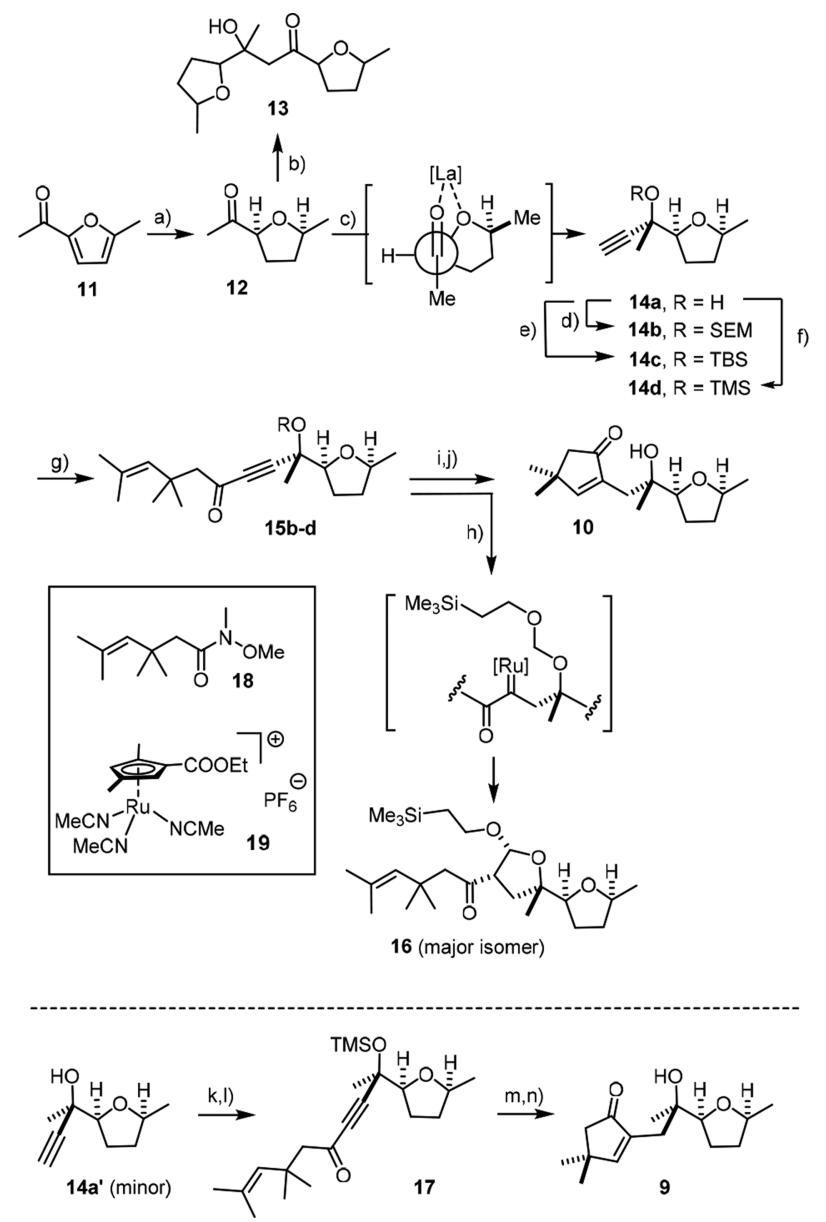

${ }^{a}$ Reagents and conditions: (a) $\mathrm{H}_{2}$ ( $\left.1 \mathrm{~atm}\right), \mathrm{Rh} / \mathrm{Al}_{2} \mathrm{O}_{3}(1 \mathrm{~mol} \%)$, $\mathrm{Et}_{2} \mathrm{O}, 59 \%$ (16 mmol scale); (b) $\mathrm{HC} \equiv \mathrm{CMgBr}$, THF, $-78^{\circ} \mathrm{C} \rightarrow \mathrm{RT}$, $44 \%(\mathrm{dr}=1.4: 1)$; (c) $\mathrm{LaCl}_{3} \cdot 2 \mathrm{LiCl}$, THF, then $\mathrm{HC} \equiv \mathrm{CMgBr}, 0{ }^{\circ} \mathrm{C}$, 66-74\% (dr = 4:1) (gram scale); (d) SEMCl, $i \mathrm{PrNEt}_{2}, \mathrm{CH}_{2} \mathrm{Cl}_{2}, 94 \%$; (e) TBSOTf, 2,6-lutidine, $\mathrm{CH}_{2} \mathrm{Cl}_{2}, 0{ }^{\circ} \mathrm{C} \rightarrow \mathrm{RT}$, 97\%; (f) TMSOTf, 2,6-lutidine, $\mathrm{CH}_{2} \mathrm{Cl}_{2}, 0{ }^{\circ} \mathrm{C}, 92 \%$; (g) $n \mathrm{BuLi}$, THF, $0{ }^{\circ} \mathrm{C}$, then $18,-78$ ${ }^{\circ} \mathrm{C}\left(-50{ }^{\circ} \mathrm{C}\right) \rightarrow \mathrm{RT}, 52 \%(15 \mathrm{~b}), 61 \%(15 \mathrm{c}), 65 \%$ (15d); (h) $\left[\mathrm{Cp}^{*} \mathrm{RuCl}\right]_{4}(2 \mathrm{~mol} \%), \mathrm{H}_{2}$ (1 atm), 1,2-dichloroethane, $70{ }^{\circ} \mathrm{C}, 68 \%$ (NMR, $\mathrm{dr}=6: 1)$; (i) $19(10 \mathrm{~mol} \%), n \mathrm{Bu}_{4} \mathrm{NCl}(12 \mathrm{~mol} \%), \mathrm{H}_{2}(1$ atm), 1,2-dichloroethane, $70{ }^{\circ} \mathrm{C}, 76 \%(\mathrm{R}=\mathrm{TMS}) ;(\mathrm{j}) \mathrm{TBAF}, \mathrm{THF}, 0$ ${ }^{\circ} \mathrm{C}$, 88\%; (k) TMSOTf, 2,6-lutidine, $\mathrm{CH}_{2} \mathrm{Cl}_{2}, 0{ }^{\circ} \mathrm{C}$, 89\%; (l) $n \mathrm{BuLi}$, THF, $0{ }^{\circ} \mathrm{C}$, then $18,-78{ }^{\circ} \mathrm{C} \rightarrow 0{ }^{\circ} \mathrm{C}, 78 \%$; (m) 19 (10 mol \%), $n \mathrm{Bu}_{4} \mathrm{NCl}(12 \mathrm{~mol} \%), \mathrm{H}_{2}$ (1 atm), 1,2-dichloroethane, $70{ }^{\circ} \mathrm{C}, 67 \%$; (n) TBAF, THF, $0{ }^{\circ} \mathrm{C}, 97 \%$.

desired cyclopentenone; rather, compound $\mathbf{1 6}$ formed by $\mathrm{C}-\mathrm{H}$ insertion of the transient carbene into the methylene subunit of the SEM group was the major product. While no such reactivity had been noticed before for any acetal-protected model compound, ${ }^{9}$ this finding prompted us to revisit catalytic hydrogenative $\mathrm{C}-\mathrm{H}$ functionalization (see below). The silyl ether analogues $\mathbf{1 5 c}$,d were both much better behaved, especially when complex 19 bearing a less electron rich $\mathrm{Cp}^{\mathrm{X}}$ ligand was used as the catalyst in combination with $n \mathrm{Bu}_{4} \mathrm{NCl}^{36}$ Under these conditions, competing over-reduction was almost completely suppressed $(<5 \%)$ and the desired metathesis products were obtained in $78 \%$ and $76 \%$ yields, respectively, despite the crowded situation. The cyclization of the diastereomeric enyne $\mathbf{1 7}$ was similarly productive. Deprotection with TBAF furnished sinularones F (10) and E (9), the 
NMR spectra of which matched the reported data (for details, see the Supporting Information). ${ }^{25}$ Therefore, we conclude that the assignment of these diastereomeric marine secondary metabolites, which had been largely based on a comparison of simulated and recorded spectra, ${ }^{25}$ is indeed correct.

Hydrogenative $\mathbf{C}-\mathrm{H}$ Insertion. As previously reported, both hydrogenative metathesis and hydrogenative cyclopropanation reactions of several acetal-containing substrates are high yielding; ${ }^{9}$ side products derived from competing $\mathrm{C}-\mathrm{H}$ functionalization have not been noticed, ${ }^{37}$ despite the fact that related piano-stool ruthenium carbenes formed by other means have previously been used exactly for this purpose. ${ }^{21,38,39}$ To explain why $\mathrm{C}-\mathrm{H}$ insertion interfered with productive metathesis upon hydrogenation of enyne $\mathbf{1 5 b}$, we reasoned that the flanking carbonyl group might play a pivotal role, in that it renders the transient carbene more highly electrophilic.

Several substrates were made to test this hypothesis (Scheme 6). Hydrogenations of ynones 20a,b and 23a,b

\section{Scheme $6^{a}$}

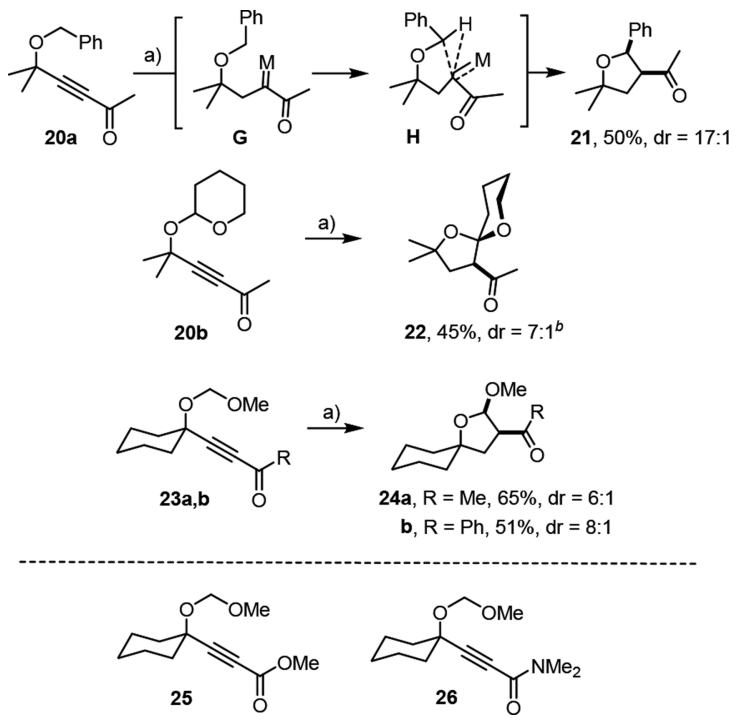

${ }^{a}$ Reagents and conditions: (a) $[\mathrm{Cp} * \mathrm{RuCl}]_{4}(2 \mathrm{~mol} \%), \mathrm{H}_{2}(1 \mathrm{~atm})$, 1,2-dichloroethane, $3 \mathrm{~h}, 70^{\circ} \mathrm{C}$. ${ }^{b}$ The product equilibrates in $\mathrm{CDCl}_{3}$ to reach this $\mathrm{dr}$ after $5 \mathrm{~h}$.

bearing different protecting groups on the propargylic alcohol substituent under standard conditions all led to $\mathrm{C}-\mathrm{H}$ insertion with formation of the corresponding tetrahydrofuran derivatives. The reactions proceed with high diastereoselectivity in favor of the cis isomers, as deduced from the NMR data; for $\mathbf{2 4 b}$, the assignment was confirmed by X-ray crystallography (see the Supporting Information). In contrast, the analogous ester (25) or amide (26) derivatives failed to afford the corresponding $\mathrm{C}-\mathrm{H}$-insertion products but merely succumbed to (over)reduction. Computations for substrate 20a suggest that the insertion reactions proceed via the concerted transition state $\mathbf{H}$ (for details, see the Supporting Information); a direct interaction of the carbonyl oxygen atom with the site of $\mathrm{C}-\mathrm{H}$ bond cleavage, as previously proposed for related transformations involving ruthenium carbenes generated by diazo decomposition, ${ }^{40}$ does not seem to play a role in this case.

Hydrogenative Metathesis of Enynes without Propargylic Substituents. Silylated alkynes are another class of substrates amenable to gem-hydrogenation. ${ }^{41}$ As one might expect, the reaction is highly regioselective in that the ruthenium carbene $\mathbf{I}$ is formed at the internal position. This regiochemical course likely reflects the hyperconjugation of the silyl group with the emerging electrophilic carbene center and predisposes the resulting $\alpha$-silylated carbene to subsequent 1,2silyl migration with the selective formation of alkenylsilanes. ${ }^{41}$

It was shown that the migratory aptitude of the silyl group is strongly dependent on the nature of the substituents at silicon in that one aryl substituent was found necessary to render the rearrangement facile. ${ }^{41}$ In consideration thereof, we reasoned that it should be possible to outperform the 1,2-silyl shift and engage an $\alpha$-silylated carbene of type I primarily formed in productive metathesis or cyclopropanation, depending on the substitution of the olefin. The examples compiled in Scheme 7

Scheme $7^{a}$
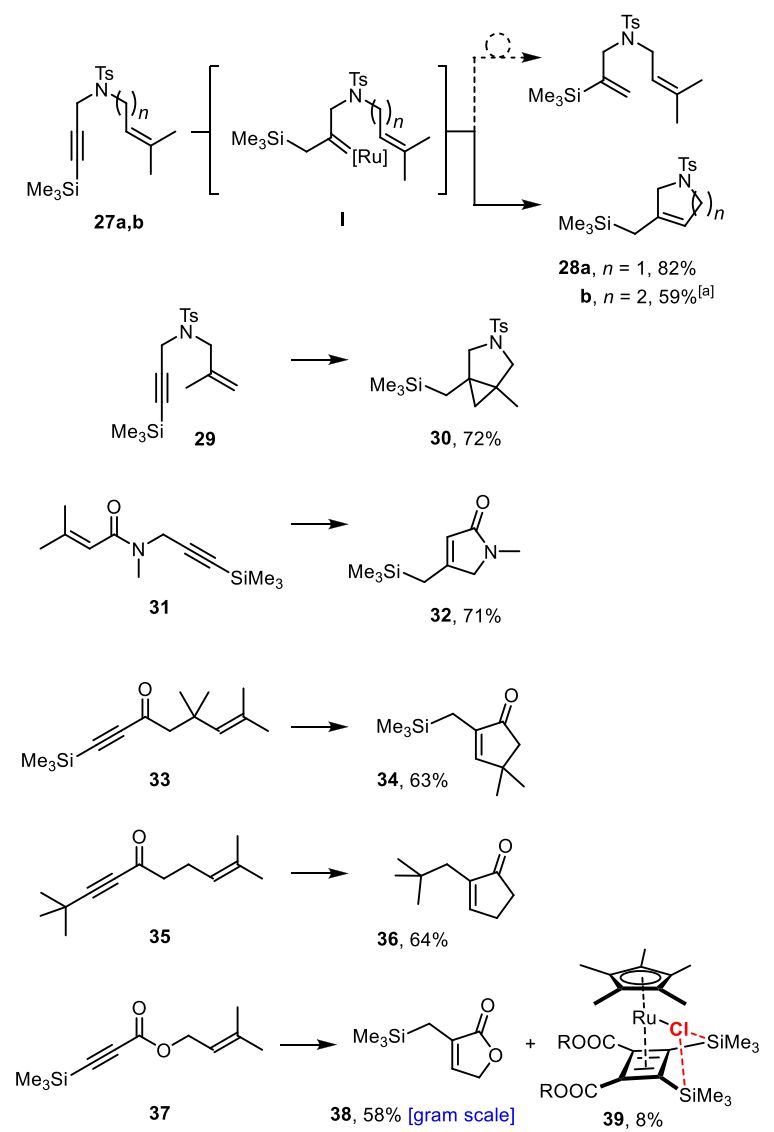

${ }^{a}$ Reagents and conditions: $[\mathrm{Cp} * \mathrm{RuCl}]_{4}(2 \mathrm{~mol} \%), \mathrm{H}_{2}$ (1 atm), 1,2dichloroethane, $3 \mathrm{~h}, 70{ }^{\circ} \mathrm{C}$. Reagents and conditions in the case of 28b: $19(20 \mathrm{~mol} \%), n \mathrm{Bu}_{4} \mathrm{NCl}(25 \mathrm{~mol} \%), \mathrm{H}_{2}$ (1 atm), 1,2dichloroethane, $8 \mathrm{~h}, 70{ }^{\circ} \mathrm{C}$.

show that this is indeed the case. Hydrogenative metathesis hence opens an entry into variously functionalized allylsilanes. The hydrogenation of enyne 35 proves that the underlying concept is not limited to silylated substrates. As expected, the reaction worked well on a gram scale, as illustrated by the formation of product 38 (the structure of this compound in the solid state is contained in the Supporting Information). In this particular reaction, complex 39 was isolated as a byproduct, which is presumably formed by oxidative cyclization of two ynoates followed by reductive elimination of the resulting ruthenacycle to give the cyclobutadiene 
ligand. ${ }^{42,43}$ While this bias is perhaps unsurprising for an electron-deficient substrate, it constitutes a major catalyst deactivation pathway because it traps no less than $\sim 50 \%$ of the initial ruthenium loading. Moreover, the fact that 39 is obtained as a single regioisomer is deemed highly significant.

The structure of $\mathbf{3 9}$ in the solid state (Figure 1) features surprisingly close contacts between the chloride ligand on

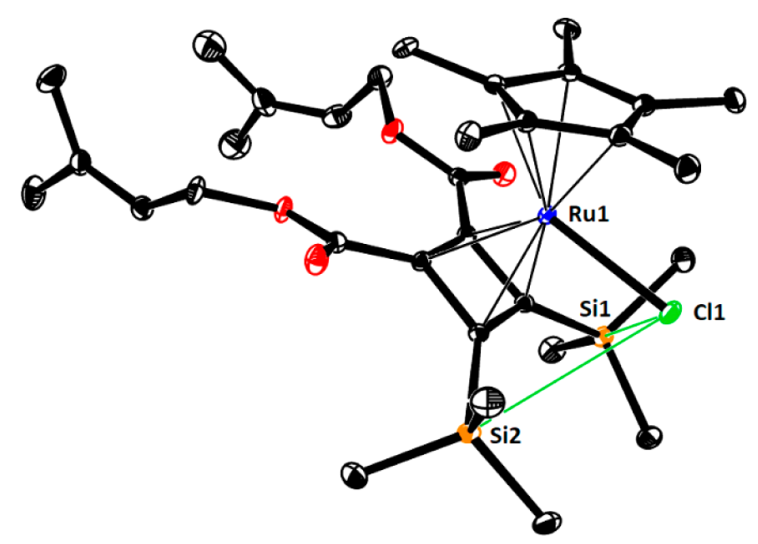

Figure 1. Structure of complex 39 in the solid state. Only one of the two independent molecules in the unit cell is shown, and hydrogen atoms are omitted for clarity. The green lines indicate attractive interactions between the polarized $[\mathrm{Ru}-\mathrm{Cl}]$ bond and the $-\mathrm{Si}\left(\mathrm{CH}_{3}\right)_{3}$ groups, partially mediated via the hydrogen atoms (cf. the text). For the full structure, see the Supporting Information.

ruthenium and the neighboring silyl groups. ${ }^{44,45}$ Specifically, the distances between the $-\mathrm{Cl}$ substiuent and the $\mathrm{H}$ atoms directed toward it are all notably short (2.8-3.1 $\AA$; sum of van der Waals radii: $3.6 \AA)^{46 a}$ and likely mediate, at least in part,

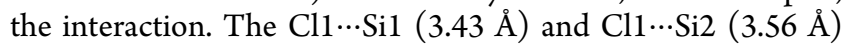
distances are also well below the sum of the van der Waals radii $\left(4.22,{ }^{46 a} 3.85 \AA^{46 b}\right)$. Interestingly, they fall into the range previously computed for an attractive through-space $[\mathrm{Ru}-$ $\mathrm{Cl}] \cdots \mathrm{Si}$ contact of this type $(3.4 \AA){ }^{48}$ however, the $\mathrm{C}-\mathrm{Si}-\mathrm{C}$ angles (average $108.5^{\circ}$ ) hardly deviate from the ideal tetrahedral geometry. The ${ }^{29} \mathrm{Si}$ NMR shift might also mirror the interaction, although this data point cannot be considered a firm proof (for details, see the Supporting Information). ${ }^{45,48}$

Under the proviso that attractive interactions of this type are operative during the upload of the substrate onto the catalyst and the ensuing transition state leading to the metallacycle, the head-to-head alignment of the silyl groups in 39 is readily explained. This observation has implications beyond this specific case: such interligand interactions had previously been invoked to explain the regiochemical course of trans-hydrosilylation reactions of unsymmetrical alkynes (Scheme 8, top) and related reactions catalyzed by $[\mathrm{Cp} * \mathrm{RuCl}]$-based catalysts. ${ }^{47-49}$ Moreover, they allow an otherwise unexplained observation reported in the literature to be rationalized: why the coupling of allyl alcohol with TMS-acetylene on the one hand and tert-butylacetylene on the other hand proceed at the opposite end of the triple bond despite the comparable steric demand (Scheme 8, bottom). ${ }^{50,51}$ Complex 39 hence corroborates the notion that interligand interactions involving a polarized $[\mathrm{Ru}-\mathrm{Cl}]$ unit are a powerful yet perhaps still underappreciated control element for different rutheniumcatalyzed transformations. ${ }^{21 a, 43,47-49}$

A Loaded Carbene Complex. As a prelude for the mechanistic studies, we sought rigorous confirmation that
Scheme 8. Examples from the Literature in which the Reaction Outcome Is Likely Determined by $\mathrm{Cl} \cdots \mathrm{Si}$ Interactions $^{a}$
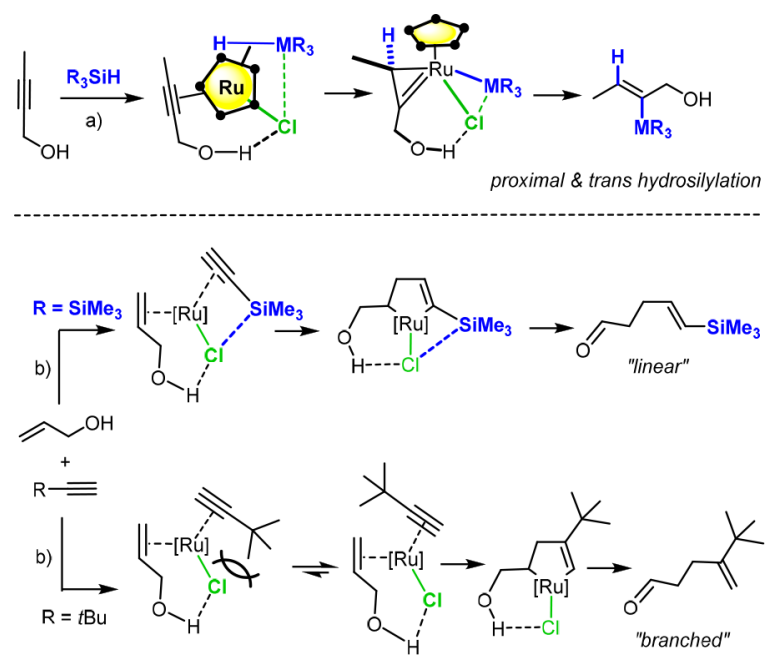

${ }^{a}$ Reagents and conditions: (a) $[\mathrm{Cp} * \mathrm{RuCl}]_{4}$ cat., $\mathrm{CH}_{2} \mathrm{Cl}_{2}$ (or pentane), see ref 47 ; (b) $[\mathrm{Cp} * \mathrm{Ru}(\operatorname{cod}) \mathrm{Cl}]$ cat., neat, see ref 50 . $\bullet$ denotes a CMe edge of the $\mathrm{Cp}^{*}$ ring in the Newman projection of the loaded catalyst and the ensuing ruthenacyclopropene.

hydrogenative metathesis as described herein proceeds via discrete ruthenium carbenes formed by gem-hydrogeantion as the key reactive intermediates. To this end, enyne 40-which is just one methylene group shorter than the model substrate $1 \mathrm{a}$-was hydrogenated with stoichiometric $[\mathrm{Cp} * \mathrm{RuCl}]_{4}(0.25$ equiv) as the precatalyst with the hope of forming a metastable carbene complex amenable to full characterization (Scheme $9):{ }^{52}$ the shortened tether should retard or even prevent

Scheme 9. Preparation of a Loaded Carbene Complex by gem-Hydrogenation

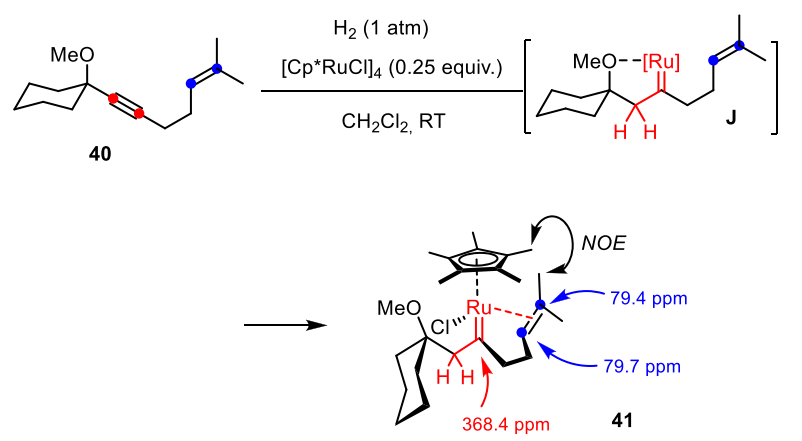

intramolecular metathesis from occurring (a strained cyclobutene ring would be formed), whereas the bulk in the first coordination sphere about the metal disfavors competing intermolecular reactions.

This expectation proved correct in that gem-hydrogenation of enyne $\mathbf{4 0}$ led to the clean formation of an intermediate $\mathbf{4 1}$ ( $\geq 95 \%$, NMR), which proved stable enough in solution for full characterization by NMR at low temperature and could even be isolated in the form of single crystals suitable for X-ray diffraction. $^{53}$ The unit cell contains no less than six independent molecules, and structure elucidation faced an additional complication of a slight modulation of the structure along the $c$ unit cell axis in that the individual molecules are 
partially replaced by their enantiomers (note that the complex is chiral-at-metal; for a discussion, see the Supporting Information); despite these complications, the structural attributes of the complex in the solid state appear to be unambiguous (Figure 2). As expected, gem-hydrogenation

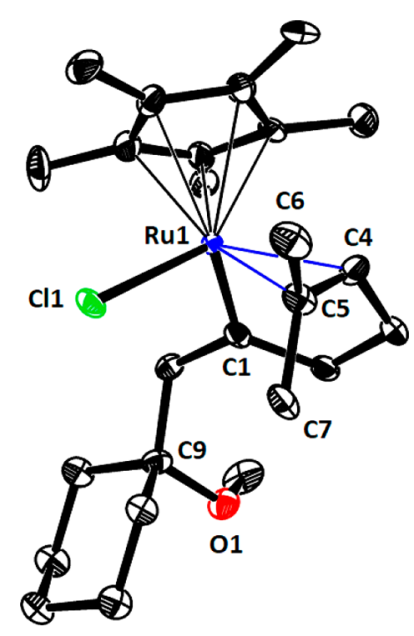

Figure 2. Structure of one of the six independent molecules of complex 41 in the solid state. Hydrogen atoms and slight disorder of $\mathrm{Ru} 1$ and $\mathrm{Cll}$ over two positions are not shown for clarity; for the entire structure and a brief discussion, see the Supporting Information

steered by the -OMe substituent has led to the regioselective formation of a piano-stool ruthenium carbene at the distal alkyne $\mathrm{C}$ atom. In the resulting 18-electron complex 41, the tethered olefin, though trisubstituted, has displaced the ether ligand in complex $\mathbf{J}$, which is thought to be initially formed by virtue of the steering -OMe substituent. The C4-C5 double bond is almost orthogonal to the $\mathrm{C} 1-\mathrm{Ru} 1$ carbene unit and experiences significant back-donation of electron density from the metal into the empty $\pi^{*}$ ligand orbital, as manifested in the elongated C4-C5 bond (1.39(4) $\AA$ ) and in the fact that the two methyl substituents (C6, C7) appear slightly out of plane; both features indicate notable rehybridization of the olefin. The structure in solution $\left(\mathrm{CD}_{2} \mathrm{Cl}_{2}\right)$ is almost certainly very similar: only one of the two methyl groups on the olefin shows a NOE contact with the methyl substituents of the $\mathrm{Cp}^{*}$ ligand, suggesting that the orientation perpendicular to the $\mathrm{C} 1-\mathrm{Ru} 1$ vector observed in the solid state is retained (Scheme 9). The signal at $\delta_{\mathrm{C}} 368.4 \mathrm{ppm}$ confirms the (Fischer) carbene nature of $41 ;{ }^{54}$ it is actually more deshielded than related halfsandwich ruthenium carbenes of type $\mathbf{J}$ in which the lateral -OMe substituent remains ligated to the metal center. ${ }^{3,7}$ The massive high-field shift of the alkene signals to $\delta_{\mathrm{C}} 79.4 / 79.7$ ppm proves that the $\pi$ system is tightly bound to the metal, even at ambient temperature, whereas the $-\mathrm{OMe}$ is off. ${ }^{55}$ This detailed structural portrayal of complex $\mathbf{4 1}$ forms a calibration point for the mechanistic discussion summarized below.

Fate of the Secondary Carbene. The isolation of 41 is consistent with the hypothesis that $[\mathrm{Cp} * \mathrm{RuCl}]$ is the catalytically active species that entails gem-hydrogenation and is accountable for the conversion of an enyne such as 1a into a cycloalkene $\mathbf{2} \mathbf{a}$ as described herein. The actual metathesis step, however, generates a secondary carbene of type 42, which must be reconverted into this active catalyst at a rate that is faster than its addition to the triple bond of unreacted substrate; otherwise, "hydrogenative metathesis" transmutes into an ordinary enyne metathesis with formation of a 1,3diene product. ${ }^{12,13}$

Privileged substrates such as 1a with two methyl groups on the alkene release $\mathbf{4 2} \mathbf{a}$ as the secondary carbene (Scheme 10).

Scheme 10. Fate of the Secondary Carbene in the Case of an Enyne Substrate with a Dimethylated Olefin

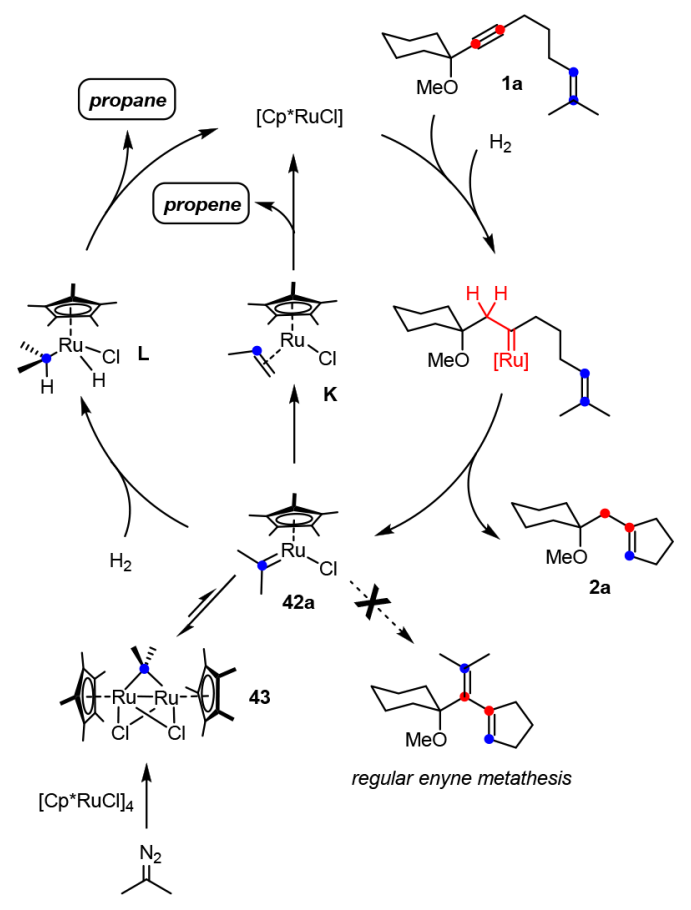

We have previously shown that $42 \mathrm{a}$ traps free [ $\mathrm{Cp} * \mathrm{RuCl}]$ to give the binuclear complex 43, held together by two bridging chloride ligands and the now equally bridging carbene unit (see the Supporting Information)., ${ }^{96}$ 43, however, is most likely a dormant rather than active species, and the turnoverlimiting step likely comes after its formation. ${ }^{9}$ At elevated temperatures, which are usually necessary for hydrogenative metathesis to proceed at a reasonable rate, $\mathbf{4 3}$ is in equilibrium with monomeric 42a: it is this latter species which reacts under a hydrogen atmosphere via $\mathbf{K}$ and $\mathbf{L}$ to give propene and propane, respectively, which represent by far the major components of the volatile fraction, as confirmed by headspace GC analysis (see the Supporting Information). ${ }^{9}$

Alkene Substitution as the Key Determinant. The representative example depicted in Scheme 2 had shown that the reaction outcome is critically dependent on the degree of substitution of the alkene unit of a given substrate. For this perplexing result, it was also deemed necessary to investigate the influence of the nature of the substituents. In this context it is important to note that changes in the substitution pattern do not only alter the sterics about and electronics of the double bond to be metathesized or cyclopropanated; in the case of metathesis, the substituents also profoundly affect the constitution and stability of the secondary carbene 42 , which must be recycled into the actual catalyst sufficiently quickly.

The examples compiled in Schemes 11 and 12 are relevant in mechanistic terms. First and foremost, the outcome of the hydrogenation with $[\mathrm{Cp} * \mathrm{RuCl}]$ is obviously not a matter of whether the double bond of the enyne is electron-rich or electron-deficient. The comparison of substrates $1 \mathrm{e}$ with an 
Scheme $11^{a}$
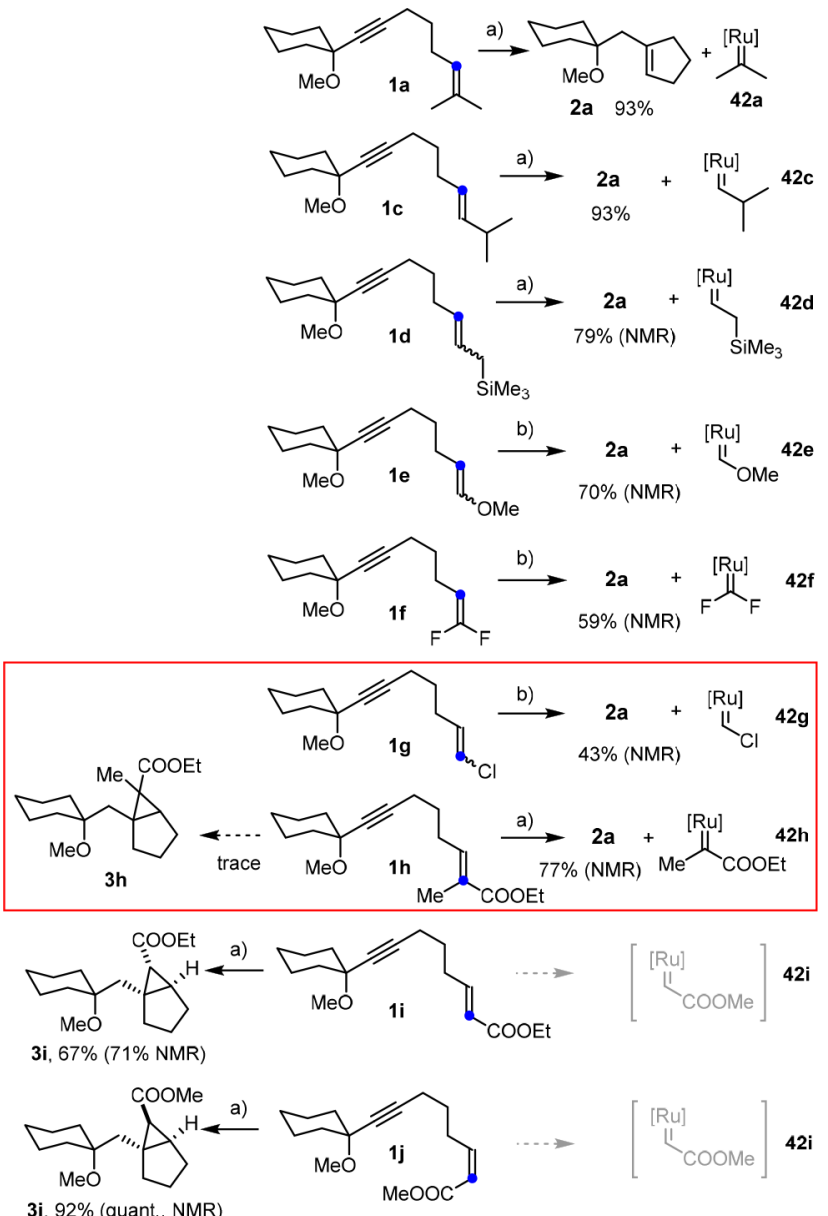

3j, $92 \%$ (quant., NMR)

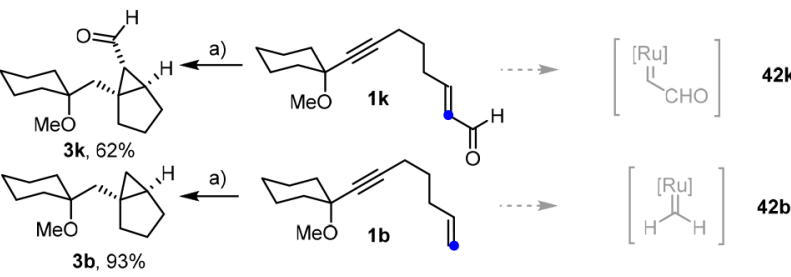

${ }^{a}$ Reagents and conditions: (a) $[\mathrm{Cp} * \mathrm{RuCl}]_{4}(2 \mathrm{~mol} \%), \mathrm{H}_{2}$ (1 atm), 1,2-dichloroethane, $3 \mathrm{~h}, 70{ }^{\circ} \mathrm{C}$; (b) $[\mathrm{Cp} * \mathrm{RuCl}]_{4}$ (0.25 equiv), $\mathrm{H}_{2}$ (1 atm), 1,2-dichloroethane, $3 \mathrm{~h}$, RT. The color-coded $\mathrm{C}$ atom denotes the more nucleophilic position of the alkene. The secondary carbenes are the proposed (catalytic) intermediates, which are shown because their stability and fate are thought to determine the course of the overall transformation (metathesis versus cyclopropanation; see the text). $[\mathrm{Ru}]=\mathrm{Cp} * \mathrm{RuCl}$.

enol ether and If containing a gem-difluoro group at the terminus illustrates this aspect: though very different in electronic terms, both substrates undergo metathesis to afford product $\mathbf{2 a}$. The resulting secondary carbenes $\mathbf{4 2 e , f}$ both carry heteroatom substituents as stabilizing $\pi$-donor ligands; ${ }^{54,57,58}$ this thermodynamic aspect notwithstanding, the good leavinggroup properties of the heteroelements open low-lying decomposition pathways which outcompete reconversion into the propagating species. ${ }^{59}$ Therefore, a stoichiometric amount of $[\mathrm{Cp} * \mathrm{RuCl}]_{4}$ was necessary to reach full conversion in both cases; as one might expect, the same is true for the alkenyl chloride derivative $\mathbf{1 g}{ }^{60}$ All other reactions shown in
Scheme $12^{a}$

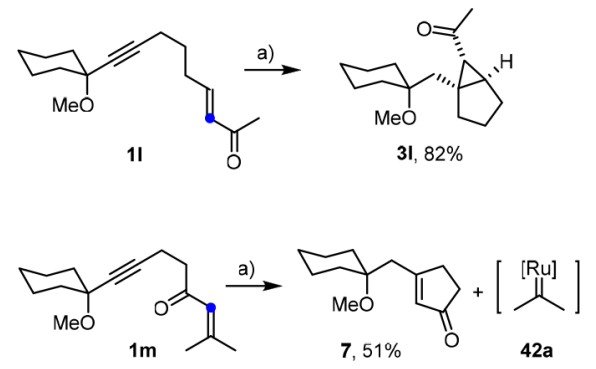

${ }^{a}$ Reagents and conditions: (a) $\left[\mathrm{Cp}^{*} \mathrm{RuCl}\right]_{4}(2 \mathrm{~mol} \%), \mathrm{H}_{2}$ (1 atm), 1,2-dichloroethane, $3 \mathrm{~h}, 70{ }^{\circ} \mathrm{C}$. The color-coded $\mathrm{C}$ atom denotes the more nucleophilic position of the alkene.

Scheme 11 are catalytic processes that proceed well under the standard conditions outlined above.

The divergent behavior of the difluoroalkene $1 f$ and compound $\mathbf{1 b}$ containing an ordinary terminal olefin is also informative: because hydrogen and fluorine are not overly different in size but the outcome of the reactions is opposite, one must conclude that the product-determining step of the catalytic cycle is (largely) governed by electronic rather than steric factors. This notion is corroborated by a comparison of 1a, 1c, and 1d, which shows that disubstitution of the olefin is also not mandatory. Equally remarkable is the striking switch observed for enoates $\mathbf{1 h}$ and $\mathbf{1} \mathbf{i}$, which differ only in the presence or absence of a single methyl group: whereas the former undergoes hydrogenative metathesis to give $2 \mathrm{a}$ and just a trace of what seems to be the corresponding cyclopropane, the nor-methyl derivative $1 \mathbf{i}$ succumbs to clean hydrogenative cyclopropanation with formation of $3 \mathbf{i}$. The reaction is stereospecific in that the $Z$ isomer $\mathbf{1 j}$ provides the diastereomeric cyclopropane $3 \mathbf{j}$, which speaks for a highly ordered selectivity-determining transition state (for details, see Computational Studies and Mechanistic Discussion). The compatibility of an aldehyde group as shown by the hydrogenative conversion of $\mathbf{1 k}$ into $3 \mathbf{k}$ is yet another noteworthy aspect.

Additional information can be deduced from the reactions shown in Scheme 12: although both substrates are enones, hydrogenation under standard conditions takes an entirely different course in that $\mathbf{1 1}$ furnishes cyclopropane $\mathbf{3 l}$ as a single diastereomer, whereas $\mathbf{1 m}$ undergoes metathesis with formation of the cyclopentenone derivative 7 .

At first sight, these examples speak for a correlation between the polarization of the double bond and the reaction outcome. If one takes the chemical shift as a proxy, ${ }^{61}$ the trisubstituted alkene in $\mathbf{1 a}$ is more nucleophilic at the internal position, whereas its cousin $\mathbf{1 b}$ is actually more nucleophilic at the terminus. If then-in accordance with "Markovnikov's rule"the prime site of attack of the olefin onto an electrophilic Fischer-type carbene changes, ${ }^{62}$ one might assume that $\mathbf{1 b}$ engages in a 6-endo-trig transition state that leads to the cyclopropane by an outer-sphere process. In contrast, 1a seems poised for an ordinary Chauvin-type mechanism via a $[2+2]$ cycloaddition/cycloreversion mechanism that ultimately results in metathesis. ${ }^{12}$ Under this proviso, one would expect that all enynes of type 1 , in which the position of the alkene proximal to the ruthenium carbene is the more nucleophilic site, will undergo metathesis, whereas the opposite polarization results in cyclopropanation. This model concurs with the fact that the 
hydrogenations of substrates $\mathbf{1 e}$ and $\mathbf{1 f}$ comprising olefins as different as an enol ether and a difluoroalkene take the same course and both result in metathesis; likewise, it predicts that the ordinary terminal alkene $\mathbf{1 b}$ and the much more electron deficient enal $\mathbf{1 k}$ both afford the corresponding cyclopropanes.

However, Scheme 11 shows two cases, which cast doubt on the view that this interpretation assuming a competing outersphere/inner-sphere mechanism captures the full picture. Specifically, alkenyl chloride $\mathbf{1 g}$ and the trisubstituted enoate $\mathbf{1 h}$ both show the "distal pattern" yet undergo metathesis (at least as the major reaction channel). ${ }^{63}$ In this context, it is also necessary to re-evaluate the small number of related examples documented in the literature in which stoichiometric reactions of preformed Fischer carbene complexes with enynes resulted in either cyclopropanation or metathesis depending on the substitution pattern (and/or the solvent). ${ }^{64-66}$ Fully convincing explanations have not been published, but it has been speculated that the stability of the secondary carbene generated in the case of metathesis might play a role in determining the reaction outcome. Although this looks-a priori-like a thermodynamic argument, it cannot be discounted in the first place but deserves further consideration.

Computational Studies and Mechanistic Discussion. To complement the experimental data and draw a more accurate picture of the underlying mechanism(s), detailed computational studies were carried out using DLPNO$\operatorname{CCSD}(\mathrm{T}) /$ def2-TZVPP single-point energies on top of B3LYP-D3/def2-TZVP(-f) geometry optimization. ${ }^{67-70}$ The perturbative triples correction was calculated using the socalled semicanonical approximation. ${ }^{71}$ Solvation effects were included at the DFT level using the implicit solvation model CPCM $\left(\mathrm{CH}_{2} \mathrm{Cl}_{2}\right) \cdot{ }^{72,73}$ An initial exploration of the chemical space $^{74}$ was carried out using the semiempirical tight-binding based quantum chemistry method GFN2-xTB. ${ }^{75}$

Substrates 1a, 1b, 1e, 1f, and $\mathbf{1 i}$ were chosen for this computational survey. First, extensive conformation sampling showed that in all cases the tethered olefin is $\eta^{2}$-ligated to the $\mathrm{Ru}$ center in the most stable carbene complex $\mathbf{A}$ formed during the gem-hydrogenation step, independent of the electronic character of the double bond. Complexes of type A, as the starting point for the computations, nicely correspond to compound $\mathbf{4 1}$ characterized by X-ray diffraction (see Figure 2). The further evolution into the cyclopropane by an outersphere mechanism, as considered in our preliminary communication with the explicit caveat that more detailed scrutiny is necessary, ${ }^{9,62}$ has a prohibitively high activation barrier $\left(>35 \mathrm{kcal} \mathrm{mol}^{-1}\right)$ and can hence be safely disregarded.

Rather, A first converts into a "kite-shaped" metallacycle $\mathbf{A}^{\prime}$ before the pathway bifurcates, in which all three $\mathrm{C}$ atoms entertain bonding interactions to the metal (Figure 3). Depending on the specific substitution pattern, $\mathbf{A}^{\prime}$ is either a regular minimum on the potential energy surface or just an "inflection point", as in the case of enyne $\mathbf{1 b}$ with the terminal alkene shown in Figure $3 .^{76}$ This distorted metallacycle $\mathbf{A}^{\prime}$ can cyclorevert via $\mathbf{T S}_{\mathrm{AB}}$ to afford the (invariant) metathesis product $\mathbf{C}$ and the corresponding secondary carbene; alternatively, it can evolve via $\mathbf{T S}_{\mathrm{AD}}$ into the "regular" metallacycle $\mathbf{D}$, which undergoes reductive elimination and releases cyclopropane $\mathbf{F}$ (this step is facilitated by agostic interactions in the transition state $\mathrm{TS}_{\mathrm{DE}}$ and the resulting adduct complex E).$^{77}$ For enyne $\mathbf{1 b}$ with the terminal alkene, $\mathrm{TS}_{\mathrm{AD}}$ leading to the cyclopropane is $1.9 \mathrm{kcal} \mathrm{mol}^{-1}$ lower in Gibbs free energy than $\mathbf{T S}_{\mathrm{AB}}$ en route to the metathesis

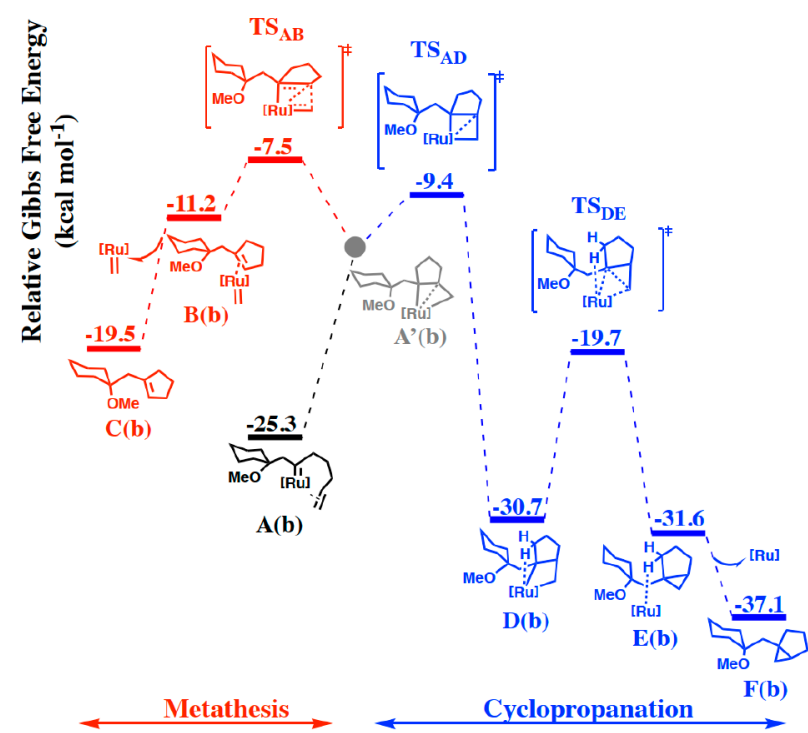

Figure 3. Metathesis versus cyclopropanation pathways for a carbene complex derived from enyne $\mathbf{1} \mathbf{b}$ with a terminal alkene; as a reference energy we used the substrate and the $[\mathrm{Cp} * \mathrm{RuCl}]$ catalyst. For the sake of simplicity, only the key intermediates and transition states along the minimum energy pathways are shown.

product; this computational result is in excellent agreement with the experimentally observed outcome. ${ }^{78}$ For the highly ordered character of the transition state leading to $\mathbf{D}$ and of the subsequent reductive elimination step, it is readily understood why cyclopropanation reactions of substituted alkenes proceed stereospecifically (compare $\mathbf{1 i}$ and $\mathbf{1 j}$ in Scheme 11; additional examples are contained in ref 9).

This basic scenario remains the same for all substrates investigated (1a, $\mathbf{1} \mathbf{b}, \mathbf{1} \mathbf{e}, \mathbf{1} \mathbf{f}$, and $\mathbf{1 i})$, but the substituents at the alkene terminus and the electronic character of the alkene massively affect the barrier heights. The case of the "isosteric" difluoroalkene derivative 1 f is representative (Figure 4; for the other cases, see the Supporting Information): the distorted metallacycle $\mathbf{A}^{\prime}(\mathbf{f})$ formed before the pathways bifurcate is a true intermediate rather than an inflection point. Once it is reached, metathesis is almost barrierless and outcompetes cyclopropanation; this computed outcome is again in accord with experiment.

It is significant that the barriers for cyclopropanation are fairly "insensitive" even for enynes comprising olefins as different as a terminal and a difluorinated alkene (15.9 and $10.6 \mathrm{kcal} \mathrm{mol}^{-1}$, respectively). ${ }^{79}$ In striking contrast, the barriers for metathesis are massively affected in that $\Delta G^{\ddagger}$ decreases from $17.8 \mathrm{kcal} \mathrm{mol}^{-1}$ for $\mathbf{1 b}$ to only $2.3 \mathrm{kcal} \mathrm{mol}^{-1}$ for 1f. The trend that the barrier for cycloreversion of the distorted metallacycle and hence metathesis is particularly responsive to changes of the substitution pattern and/or polarization of the olefin (as manifested in the NPA charges) pertains to all substrates investigated (Table 1): in essence, it is this effect that determines the outcome. ${ }^{80}$

This computational result warrants further consideration, as does that fact that the path leading to the cyclopropane passes through two distinctly different metallacycles, whereas metathesis involves only one. It is well established in the literature that metallacyclobutanes in general fall into two different categories (Figure 5). ${ }^{81-83}$ One type features a significant agostic interaction between the metal and the $\mathrm{C}_{\beta}$ atom, which in turn results in a short $M \cdots C_{\beta}$ contact, weakened $C_{\alpha}-C_{\beta}$ 


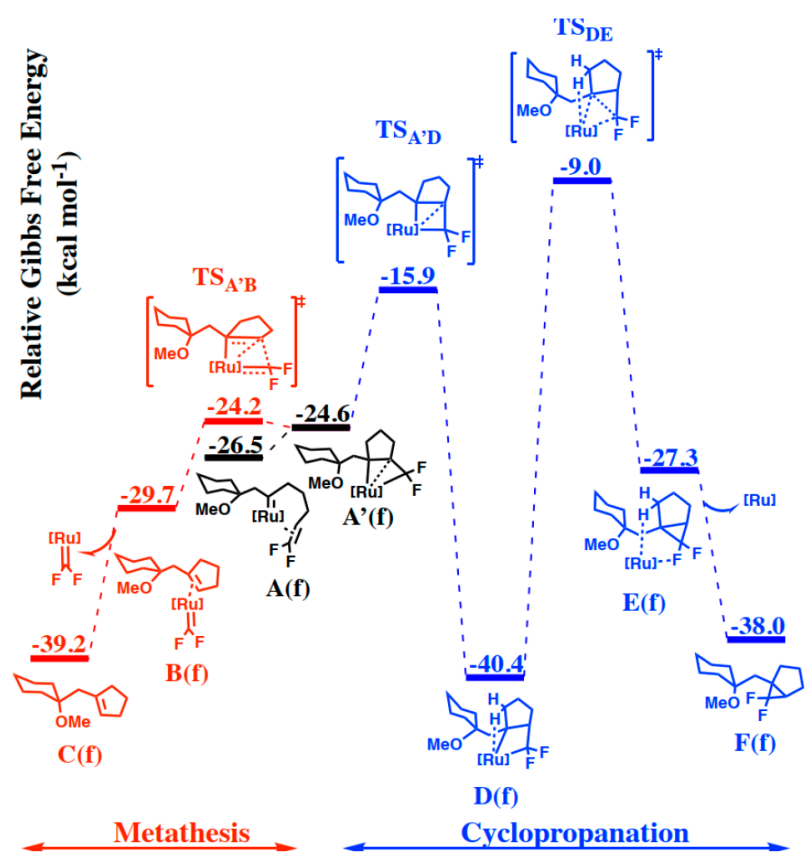

Figure 4. Metathesis versus cyclopropanation pathways for a carbene complex derived from enyne If with a difluoroalkene moiety; as a reference energy, we used the substrate and the $[\mathrm{Cp} * \mathrm{RuCl}]$ catalyst.

bonds, and notable alkylidene character at $\mathrm{C}_{\alpha} / \mathrm{C}_{\alpha^{\prime}}$; metallacycles of this sort are prone to cycloreversion. The other type of metallacyclobutanes, in contrast, lacks the $\mathrm{M} \cdots \mathrm{C}_{\beta}$ agostic interaction and the other characteristics that it entails; most notably, their $\mathrm{C}_{\alpha}$ atoms do not have any significant alkylidene character. Intermediates of this latter type easily succumb to $\beta$ $\mathrm{H}$-elimination reactions or reductive elimination.

Figure 5 depicts the computed ruthenacyclobutane substructure of complexes $\mathbf{A}^{\prime}(\mathbf{b})$ and $\mathbf{D}(\mathbf{b})$ derived from enyne $\mathbf{1} \mathbf{b}$. From the overall geometries and metric data it is obvious that they correspond very well to the two extremes: for the "kiteshaped" metallacycle $\mathbf{A}^{\prime}(\mathbf{b})$ to transform into $\mathbf{D}(\mathbf{b})$, it must undergo a change in bonding (loss of the $\beta$-agostic interaction) accompanied by a significant change in geometry, which actually brings the $\mathrm{C}_{\alpha} / \mathrm{C}_{\alpha^{\prime}}$ atoms closer together (for further details, see the Supporting Information). Only after $\mathbf{D}(\mathbf{b})$ is reached can reductive elimination with formation of the cyclopropane occur. It is intuitive that any substitution pattern on the ring that increases the alkylidene character of the $\mathrm{Ru}-$ $\mathrm{C}_{\alpha}$ bond of $\mathbf{A}^{\prime}(\mathbf{b})$ will disfavor this process relative to $[2+2]$

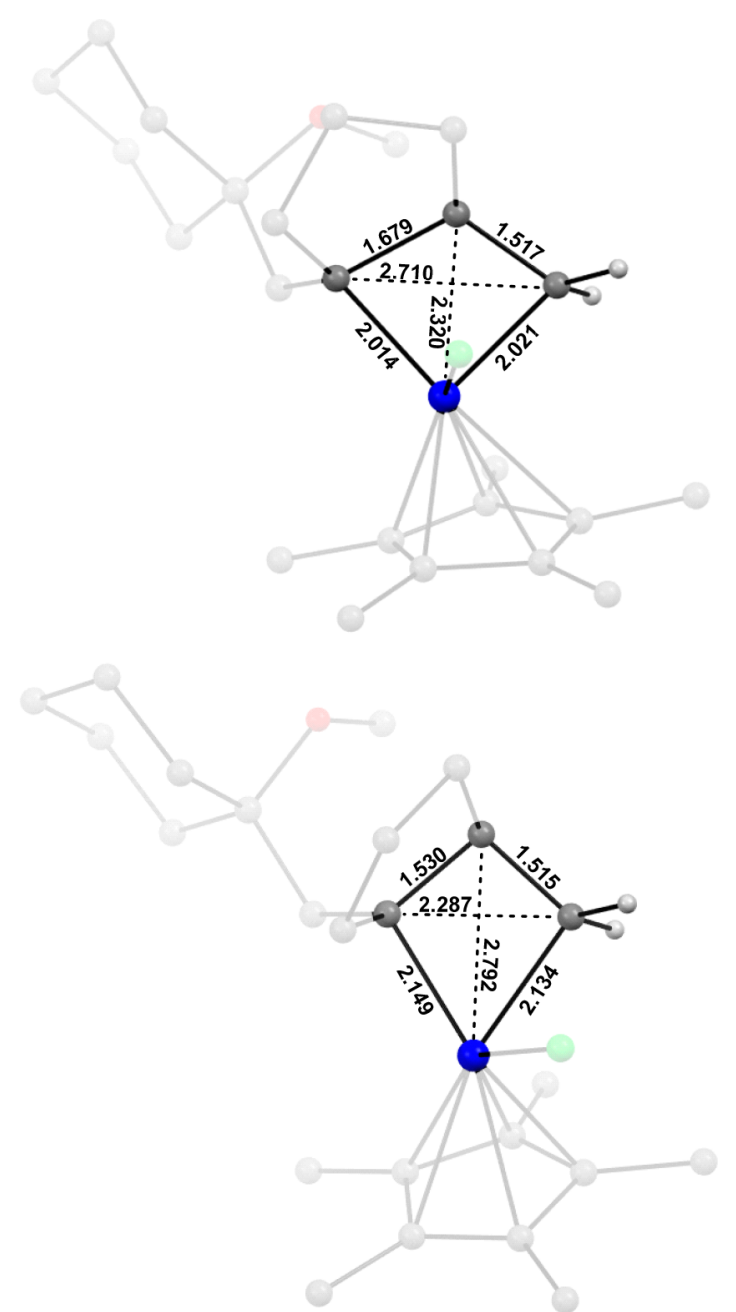

Figure 5. Computed structures of the ruthenacyclobutane entites of complexes $\mathbf{A}^{\prime}(\mathbf{b})$ (top) and $\mathbf{D}(\mathbf{b})$ (bottom) derived from enyne $\mathbf{1 b}$ with the terminal alkene. Distances are given in $\AA$.

cycloreversion: a $\pi$-donor substituent and/or an appropriately polarized double bond fall into this category. ${ }^{54-57}$

It is equally important to recognize that a (heteroelement) substituent at $\mathrm{C}_{\alpha}$ that increases the carbene (alkylidene) character of the metallacycle $\mathbf{A}^{\prime}$ and therefore favors metathesis also translates into the thermodynamically more stable secondary carbene $\mathbf{4 2}$. The significant lowering of the barrier heights of $\mathrm{TS}_{\mathrm{AB}}$ on the metathesis pathway can hence be seen as an illustration of the Bell-Evans-Polanyi principle, which

Table 1. Computed Barriers That Determine the Evolution of the Ruthenium Carbene Complex A Primarily Formed ${ }^{a}$

\begin{tabular}{|c|c|c|c|c|c|c|c|c|}
\hline \multirow[b]{2}{*}{ substrate } & \multirow[b]{2}{*}{ terminus } & \multicolumn{2}{|c|}{$Q$} & \multirow[b]{2}{*}{$\begin{array}{l}\Delta G^{\ddagger}\left(\mathrm{TS}_{\mathrm{AB}}\right)^{b} \\
\left(\mathrm{kcal} \mathrm{mol}^{-1}\right)\end{array}$} & \multirow[b]{2}{*}{$\underset{\left(\mathrm{kcal} \mathrm{mol}^{-1}\right)}{\Delta G^{\ddagger}\left(\mathrm{TS}_{\mathrm{AD}}\right)^{c}}$} & \multirow[b]{2}{*}{$\begin{array}{l}\Delta G(\mathbf{A} \rightarrow \mathbf{C})^{d} \\
\left(\mathrm{kcal} \mathrm{mol}^{-1}\right)\end{array}$} & \multicolumn{2}{|c|}{ outcome } \\
\hline & & at $\mathrm{C} 1$ & at $\mathrm{C} 2$ & & & & predicted & exptl \\
\hline $1 b$ & $-\mathrm{CH}=\mathrm{CH}_{2}$ & -0.39 & -0.17 & 17.8 & 15.9 & +5.8 & cycloprop & cycloprop \\
\hline $1 \mathrm{i}$ & $-\mathrm{CH}=\mathrm{CHCOOEt}$ & -0.32 & -0.08 & 21.4 & 11.2 & +6.6 & cycloprop & cycloprop \\
\hline 1a & $-\mathrm{CH}=\mathrm{CMe}_{2}$ & +0.02 & -0.20 & 10.8 & 21.6 & -4.1 & metathesis & metathesis \\
\hline If & $-\mathrm{CH}=\mathrm{CF}_{2}$ & +0.72 & -0.36 & 2.3 & 10.6 & -12.7 & metathesis & metathesis \\
\hline 1e & $-\mathrm{CH}=\mathrm{CH}(\mathrm{OMe})$ & +0.12 & -0.28 & 3.7 & 15.5 & -7.7 & metathesis & metathesis \\
\hline
\end{tabular}

${ }^{a} \mathrm{Q}$ denotes the NPA (natural population analysis) charge at the "terminal" $(\mathrm{C} 1)$ and internal $(\mathrm{C} 2)$ atom of the olefin. ${ }^{b} \mathrm{TS}_{\mathrm{AB}}$ refers to the cycloreversion step and hence the reaction channel resulting in metathesis. ${ }^{c} \mathbf{T S}_{\mathrm{AD}}$ is the first transition state toward cyclopropanation, which may or may not be the highest barrier of this pathway; see the Supporting Information. ${ }^{d}$ Thermochemistry associated with the transformation of the primary carbene into the metathesis product 2 a together with the corresponding secondary carbene (C). 
links the energy of the transition state to the energy of the subsequent intermediate (Figure 6). ${ }^{84}$ Since all hydrogenations

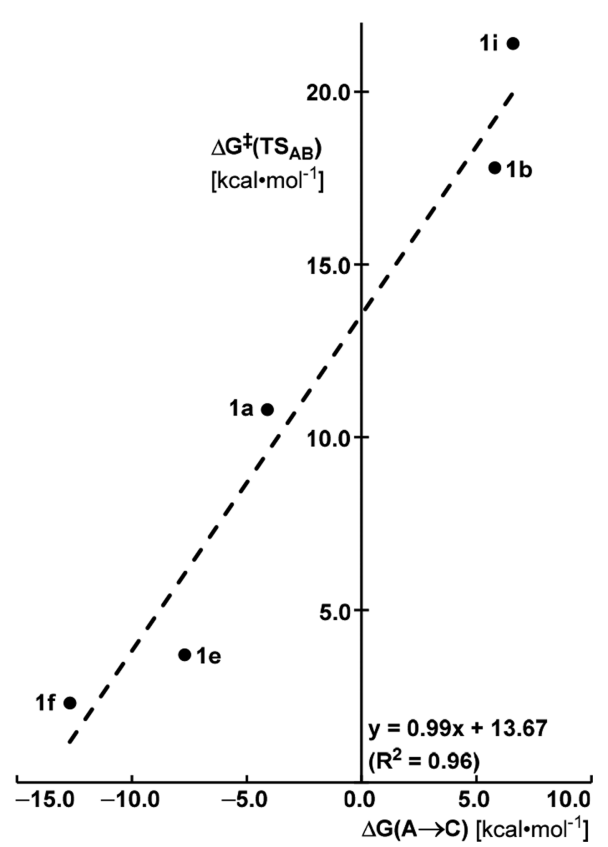

Figure 6. Illustration of the Bell-Evans-Polanyi principle. The barrier height for cycloreversion $\left(\Delta G^{\ddagger}\left(\mathbf{T S}_{\mathrm{AB}}\right)\right)$ correlates with the stability of the secondary carbene complex released together with the invariant metathesis product $((\Delta G(\mathbf{A} \rightarrow \mathbf{C}))$ : a more exergonic cycloreversion process exhibits a lower activation barrier (the energies relative to the initial carbene complex $\mathbf{A}$ ).

shown in Scheme 11 form the same metathesis product 2a, it is the stability of the secondary carbene $42 a-k$ which makes the key difference because it manifests itself already in the transition state: in cases in which the secondary carbene is destabilized (shaded in gray), $\mathbf{T S}_{\mathbf{A B}}$ is expected to be high in energy and metathesis is hence prevented.

In a view through this lens, one may conclude that the original proposals made in the literature that the polarization of the double bond of the substrate or the stability of the secondary carbene determines the course of the reaction are both correct in a way, even though it took the computations to understand why that is the case. The insight that the BellEvans-Polanyi principle intimately connects the substitution pattern with the critically responsive barrier height of the metathesis pathway results in a rather intuitive model based on an assessment of the substrate's ground state, which allows the outcome of the reactions to be predicted with confidence; it forms a sound basis that should encourage the practitioners to implement gem-hydrogenations into increasingly complex settings. In any case, ongoing work in this laboratory intends to widen the scope of this unusual novel entry into the realm of transition-metal carbenes and to refine our understanding of the underlying principles.

\section{CONCLUSIONS}

The gem-hydrogenation of internal alkynes is a fundamentally new transformation that gives access to discrete metal carbene complexes for use in synthesis. For substrates that contain a tethered alkene, the piano-stool carbene intermediates derived from $[\mathrm{Cp} * \mathrm{RuCl}]$ as the privileged catalyst can undergo cyclopropanation or metathesis reactions. The outcome is largely determined by the substitution pattern of the olefin, which is a perplexing result at first sight. A systematic investigation in combination with computational study allowed the seemingly bewildering results to be sorted and an intuitive model to be deduced, which allows the course of the reaction to be predicted on the basis of the substitution pattern of the substrate. The computational data find excellent correspondence in a half-sandwich carbene complex, in which the olefinic partner is coordinated to the ruthenium center, which represents the "loaded" catalyst and which was fully characterized by spectroscopic and crystallographic means. A first application to the total synthesis of two diastereomeric marine natural products illustrates the virtues of this methodology, as does a new hydrogenative entry into allylsilanes, which are valuable building blocks in organic synthesis.

\section{ASSOCIATED CONTENT}

\section{Supporting Information}

(PDF) Copies of (PDF) Crystallographic data (CIF) The Supporting Information is available free of charge at https:// pubs.acs.org/doi/10.1021/jacs.0c07808.

Experimental section containing supporting X-ray structures and crystallographic information, characterization data, and computational details (PDF)

NMR spectra of new compounds (PDF)

Crystallographic data (CIF)

Crystallographic data (CIF)

Crystallographic data (CIF)

Crystallographic data (CIF)

Crystallographic data (CIF)

Crystallographic data (CIF)

\section{AUTHOR INFORMATION}

\section{Corresponding Author}

Alois Fürstner - Max-Planck-Institut für Kohlenforschung, 45470 Mülheim/Ruhr, Germany; ○ orcid.org/0000-0003-

0098-3417; Email: fuerstner@kofo.mpg.de

\section{Authors}

Sebastian Peil - Max-Planck-Institut für Kohlenforschung, 45470 Mülheim/Ruhr, Germany

Giovanni Bistoni - Max-Planck-Institut für Kohlenforschung, 45470 Mülheim/Ruhr, Germany; 이이이.org/0000-00034849-1323

Richard Goddard - Max-Planck-Institut für Kohlenforschung, 45470 Mülheim/Ruhr, Germany; (1) orcid.org/0000-00030357-3173

Complete contact information is available at:

https://pubs.acs.org/10.1021/jacs.0c07808

\section{Notes}

The authors declare no competing financial interest.

\section{ACKNOWLEDGMENTS}

Generous financial support by the MPG is gratefully acknowledged. We thank Dr. A. Guthertz and Mr. T. Biberger for early experimental contributions and discussions and all analytical departments of our Institute for valuable support, especially Mr. J. Rust and Prof. C. W. Lehmann, for excellent $\mathrm{X}$-ray service. 


\section{REFERENCES}

(1) Fürstner, A. trans-Hydrogenation, gem-Hydrogenation, and trans-Hydrometalation of Alkynes: An Interim Report on an Unorthodox Reactivity Paradigm. J. Am. Chem. Soc. 2019, 141, 1124.

(2) Leutzsch, M.; Wolf, L. M.; Gupta, P.; Fuchs, M.; Thiel, W.; Farès, C.; Fürstner, A. Formation of Ruthenium Carbenes by gemHydrogen Transfer to Internal Alkynes: Implications for Alkyne transHydrogenation. Angew. Chem., Int. Ed. 2015, 54, 12431-12436.

(3) Guthertz, A.; Leutzsch, M.; Wolf, L. M.; Gupta, P.; Rummelt, S. M.; Goddard, R.; Farès, C.; Thiel, W.; Fürstner, A. Half-Sandwich Ruthenium Carbene Complexes Link trans-Hydrogenation and gemHydrogenation of Internal Alkynes. J. Am. Chem. Soc. 2018, 140, 3156-3159.

(4) Radkowski, K.; Sundararaju, B.; Fürstner, A. A Functional-Group Tolerant Catalytic trans-Hydrogenation of Alkynes. Angew. Chem. 2013, 125, 373-378.

(5) Fürstner, A.; Davies, P. W. Catalytic Carbophilic Activation: Catalysis by Platinum and Gold $\pi$-Acids. Angew. Chem., Int. Ed. 2007, $46,3410-3449$

(6) A ruthenacyclopropane had previously been proposed as the key intermediate of related trans-hydrosilylation reactions. See: Chung, L. W.; Wu, Y.-D.; Trost, B. M.; Ball, Z. T. A Theoretical Study on the Mechanism, Regiochemistry, and Stereochemistry of Hydrosilylation Catalyzed by Cationic Ruthenium complexes. J. Am. Chem. Soc. 2003, $125,11578-11582$.

(7) Biberger, T.; Gordon, C.; Leutzsch, M.; Peil, S.; Guthertz, A.; Copéret, C.; Fürstner, A. Alkyne gem-Hydrogenation: Formation of Pianostool Ruthenium Carbene Complexes and Analysis of Their Chemical Character. Angew. Chem., Int. Ed. 2019, 58, 8845-8850.

(8) Peil, S.; Fürstner, A. Mechanistic Divergence in the Hydrogenative Synthesis of Furans and Butenolides: Ruthenium Carbenes Formed by gem-Hydrogenation or via Carbophilic Activation of Alkynes. Angew. Chem., Int. Ed. 2019, 58, 18476-18481.

(9) Peil, S.; Guthertz, A.; Biberger, T.; Fürstner, A. Hydrogenative Cyclopropanation and Hydrogenative Metathesis. Angew. Chem., Int. Ed. 2019, 58, 8851-8856.

(10) These reactions are counterintuitive in that cyclopropanes are usually cleaved rather than formed by catalytic hydrogenation.

(11) For a second, light-driven system, see: Biberger, T.; Zachmann, R. J.; Fürstner, A. Angew. Chem., Int. Ed. 2020, 59, 18423-18429.

(12) Handbook of Metathesis, 2nd ed.; Grubbs, R. H., O'Leary, D. J., Eds.; Wiley-VCH: Weinheim, 2015.

(13) (a) Diver, S. T.; Giessert, A. J. Enyne Metathesis (Enyne Bond Reorganization). Chem. Rev. 2004, 104, 1317-1382. (b) Hansen, E. C.; Lee, D. Search for Solutions to the Reactivity and Selectivity Problems in Enyne Metathesis. Acc. Chem. Res. 2006, 39, 509-519.

(14) Analogous substrates with a single $\mathrm{Me}-(\mathrm{Et}-)$ group on the alkene furnished product mixtures; see ref 9 .

(15) Prenyl groups and related 1,1-dimethylated alkenes are good substrates in Grubbs catalysis as well. Compare: (a) Bahou, K. A.; Braddock, D. C.; Meyer, A. G.; Savage, G. P. Kinetic Benchmarking Reveals the Competence of Prenyl Groups in Ring-Closing Metathesis. Org. Lett. 2017, 19, 5332-5353. (b) Fürstner, A.; Dierkes, T.; Thiel, O. R.; Blanda, G. Total Synthesis of (-)-Salicylihalamide. Chem. - Eur. J. 2001, 7, 5286-5298.

(16) (a) Monnier, F.; Vovard-Le Bray, C.; Castillo, D.; Aubert, V.; Derien, S.; Dixneuf, P. H.; Toupet, L.; Ienco, A.; Mealli, C. Selective Ruthenium-Catalyzed Transformations of Enynes with Diazoalkanes into Alkenylbicyclo][3.1.0] hexanes. J. Am. Chem. Soc. 2007, 129, 6037-6049. (b) Vovard-Le Bray, C.; Derien, S.; Dixneuf, P.; Murakami, M. A Direct Synthesis of Alkenyl Alkylidene Bicyclo[3.1.0] hexane Derivatives via Ruthenium(II)-Catalysed Bicyclisation of Allenynes. Synlett 2008, 2008, 193-196.

(17) Reference 16a contains a single example which gave a product mixture formed by cyclopropanation and competing metathesis; interestingly, the substrate contained a 1,1-dimethylated alkene unit. See also: Basato, M.; Tubaro, C.; Biffis, A.; Bonato, M.; Buscemi, G.; Lighezzolo, F.; Lundardi, P.; Vianini, C.; Benetollo, F.; Del Zotto, A
Reactions of Diazo Compounds with Alkenes Catalysed by [RuCl$(\operatorname{cod})(\mathrm{Cp})]$ : Effect of the Substituents in the Formation of Cyclopropanation or Metathesis Products. Chem. - Eur. J. 2009, 15, $1516-1526$.

(18) Tanaka, D.; Sato, Y.; Mori, M. Unpredicted Cyclization of an Enyne Having a Keto-Carbonyl Group on an Alkyne Using a Ruthenium Catalyst under Ethylene Gas. Organometallics 2006, 25, 799-801.

(19) Trost, B. M.; Breder, A.; O’Keefe, B. M.; Rao, M.; Franz, A. W. Propargyl Alcohols as $\beta$-Oxocarbenoid Precursors for the RutheniumCatalyzed Cyclopropanation of Unactivated Olefins by Redox Isomerization. J. Am. Chem. Soc. 2011, 133, 4766-4769.

(20) For $[\mathrm{Cp} * \mathrm{Ru}]$-derived ruthenacyclopentadienes as dicarbene equivalents in cyclopropanation, see: (a) Yamamoto, Y.; Arakawa, T.; Ogawa, R.; Itoh, K. Ruthenium(II)-Catalyzed Selective Intramolecular $[2+2+2]$ Alkyne Cyclotrimerizations. J. Am. Chem. Soc. 2003, 125, 12143-12160. (b) Schmid, R.; Kirchner, K. RutheniumMediated C-C Coupling Reactions of Alkynes - The Key Role of Ruthenacyclopentatriene Complexes. Eur. J. Inorg. Chem. 2004, 2004, 2609-2626.

(21) For reviews of yet other reactivity of such species, see: (a) Padin, D.; Varela, J. A.; Saá, C. Cp*RuCl-Vinyl Carbenes: Two Faces and the Bifunctional Role in Catalytic Processes. Chem. - Eur. J. 2020, 26, 7470-7478. (b) Padin, D.; Varela, J. A.; Saá, C. Recent Advances in Ruthenium-Catalyzed Carbene/Alkyne Metathesis (CAM) Transformations. Synlett 2020, 31, 1147-1157. (c) Dey, S.; De Sarkar, S. Synthetic Applications of Vinyl Ruthenium Carbenes Derived from Diazoalkanes and Alkynes. Adv. Synth. Catal. 2017, 359, 2709-2722. (d) Pei, C.; Zhang, C.; Qian, Y.; Xu, X. Catalytic Carbene/Alkyne Metathesis (CAM): A Versatile Strategy from Alkyne Bifunctionalization. Org. Biomol. Chem. 2018, 16, 86778685. (e) Torres, O.; Pia-Quintana, A. The Rich Reactivity of Transition Metal Carbenes with Alkynes. Tetrahedron Lett. 2016, 57, 3881-3891.

(22) For representative examples showing the tight binding of arenes or dienes to $\left[\mathrm{Cp}^{\mathrm{X}} \mathrm{Ru}\right.$ ] fragments, see: (a) Gill, T. P.; Mann, K. R. Photochemical Properties of the Cyclopentadienyl $\left(\eta^{6}\right.$-benzene)ruthenium(II) cation. The Synthesis and Reactions of a Synthetically Useful Intermediate: the Cyclopentadienyltris(acetonitrile)ruthenium(II) cation. Organometallics 1982, 1, 485-488. (b) Fagan, P. J.; Ward, M. D.; Calabrese, J. C. Molecular Engineering of SolidState Materials: Organometallic Building Blocks. J. Am. Chem. Soc. 1989, 111, 1698-1719. (c) Steines, S.; Englert, U.; Drießen-Hölscher, B. Stereoselective Catalytic Hydrogenation of Sorbic Acid and Sorbic Alcohol with New Cp*Ru Complexes. Chem. Commun. 2000, 217218.

(23) Fürstner, A. Olefin Metathesis and Beyond. Angew. Chem., Int. Ed. 2000, 39, 3012-3043.

(24) See also: Fürstner, A.; Thiel, O. R.; Ackermann, L.; Schanz, H.J.; Nolan, S. P. Ruthenium Carbene Complexes with $N, N^{\prime}$ Bis(mesityl)imidazol-2-ylidene Ligands: RCM Catalysts of Extended Scope. J. Org. Chem. 2000, 65, 2204-2207.

(25) Shi, H.; Yu, s.; Liu, D.; van Ofwegen, L.; Proksch, P.; Lin, W. Sinularones A-I, New Cyclpentenone and Butenolide Derivatives from a Marine Soft Coral Sinularia sp. and Their Antifouling Activity. Mar. Drugs 2012, 10, 1331-1344.

(26) For a recent study on another secondary metabolite derived from a Sinularia sp, see: Meng, Z.; Fürstner, A. Total Synthesis of (-)-Sinulariadiolide. A Transannular Approach. J. Am. Chem. Soc. 2019, 141, 805-809.

(27) The formation of kinetically stable chelate complexes is a major issue for first-generation Grubbs catalysts. See: (a) Fürstner, A.; Langemann, K. Total Synthesis of (+)-Ricinelaidic Acid Lactone and of (-)-Gloeosporone Based on Transition Metal Catalyzed C-CBond Formations. J. Am. Chem. Soc. 1997, 119, 9130-9136. (b) Fürstner, A.; Thiel, O. R.; Lehmann, C. W. Study Concerning the Effects of Chelation on the Structure and Catalytic Activity of Ruthenium Carbene Complexes. Organometallics 2002, 21, 331-335. 
(28) Compare: Arco, M. J.; Trammell, M. H.; White, J. D. Synthesis of ( \pm )-Nonactic Acid. J. Org. Chem. 1976, 41, 2075-2083.

(29) Zaera, F. The Surface Chemistry of Metal-Based Hydrogenation Catalysis. ACS Catal. 2017, 7, 4947-4967.

(30) Krasovskiy, A.; Kopp, F.; Knochel, P. Soluble Lanthanide Salts $\left(\mathrm{LnCl}_{3} \cdot 2 \mathrm{LiCl}\right)$ for the Improved Addition of Organomagnesium Reagents to Carbonyl Compounds. Angew. Chem., Int. Ed. 2006, 45, 497-500.

(31) See also: Jung, M. E.; Pontillo, J. Synthetic Approach to Analogues of the Original Structure of Sclerophytin A. J. Org. Chem. 2002, 67, 6848-6851.

(32) (a) Mengel, A.; Reiser, O. Around and Beyond Cram's Rule. Chem. Rev. 1999, 99, 1191-1223. (b) Reetz, M. T. Chelation or NonChelation Control in Addition Reactions of Chiral $\alpha$ - and $\beta$ - Alkoxy Carbonyl Compounds. Angew. Chem., Int. Ed. Engl. 1984, 23, 556569.

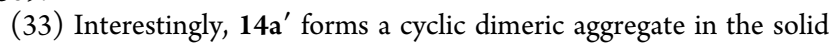
state via intermolecular hydrogen bonding, whereas 14a leads to a hydrogen-bonded polymeric array; see the Supporting Information.

(34) Unprotected propargyl alcohols favor carbene formation at the proximal C-atom or provide mixtures; cf. ref 3.

(35) The Weinreb amide was obtained from the ethyl ester $\left(\mathrm{MeNH}(\mathrm{OMe}) \cdot \mathrm{HCl}, i \operatorname{PrMgCl}, \mathrm{THF},-20^{\circ} \mathrm{C} 95 \%\right)$; see the Supporting Information. For the preparation of the ester, see: Kelkar, S. V.; Arbale, A. A.; Joshi, G. S.; Kulkarni, G. H. Claisen Orthoester Rearrangement Reaction with Seondary \& Tertiary Allylic Alcohols: Synthesis of 1,2-Seco-Crysanthemates and Their Structural Analogues. Synth. Commun. 1990, 20, 839-847.

(36) Spectroscopic and electrochemical data showed that less electron rich $\mathrm{Cp}^{\mathrm{x}}$ ligands favor gem-hydrogenation and render the resulting carbenes more stable; see ref 7 . In line with this notion, the combination of 19 and $n \mathrm{Bu}_{4} \mathrm{NCl}$ often leads to superior results; see ref 9 .

(37) A singular attempt at triggering $\mathrm{C}-\mathrm{H}$ insertion by alkyne gemhydrogenation failed; see ref 3 .

(38) (a) Cambeiro, F.; López, S.; Varela, J. A.; Saá, C. Cyclization by Cationic Ruthenium Carbene Insertion into $\mathrm{C}_{\mathrm{sp} 3}-\mathrm{H}$ Bonds. Angew. Chem., Int. Ed. 2012, 51, 723-727. (b) Cambeiro, F.; MartínezNúñez, E.; Varela, J. A.; Saá, C. DFT and Kinetic Monte Carlo Study of TMS-Substituted Ruthenium Vinyl Carbenes: Key Intermediates for Stereoselective Cyclizations. ACS Catal. 2015, 5, 6255-6262.

(39) For a general review, see: Doyle, M. P.; Duffy, R.; Ratnikov, M.; Zhou, L. Catalytic Carbene Insertion into $\mathrm{C}-\mathrm{H}$ Bonds. Chem. Rev. 2010, 110, 704-724.

(40) Tortoreto, C.; Achard, T.; Zeghida, W.; Austeri, M.; Guénée, L.; Lacour, J. Enol Acetal Synthesis through Carbenoid $\mathrm{C}-\mathrm{H}$ Insertion into Tetrahydrofuran Catalyzed by $\mathrm{CpRu}$ Complexes. Angew. Chem., Int. Ed. 2012, 51, 5847-5851.

(41) Song, L.; Feng, Q.; Wang, Y.; Ding, S.; Wu, Y.-D.; Zhang, X.; Chung, L. W.; Sun, J. Ru-Catalyzed Migratory Geminal Semihydrogenation of Internal Alkynes to Terminal Olefins. J. Am. Chem. Soc. 2019, 141, 17441-17451.

(42) Trost, B. M.; Frederiksen, M. U.; Rudd, M. T. RutheniumCatalyzed Reactions - A Treasure Trove of Atom-Economic Transformations. Angew. Chem., Int. Ed. 2005, 44, 6630-6666.

(43) Rummelt, S. M.; Cheng, G.-J.; Gupta, P.; Thiel, W.; Fürstner, A. Hydroxy-Directed Ruthenium-Catalyzed Alkene/Alkyne Coupling: Increased Scope, Stereochemical Implications, and Mechanistic Rationale. Angew. Chem., Int. Ed. 2017, 56, 3599-3604;corrigendum: Angew. Chem., Int. Ed. 2017, 56, 5652.

(44) An analogous head-to-head complex derived from TMSacetylene was characterized by X-ray diffraction, but the $-\mathrm{Cl} \cdots$. $\mathrm{Si}\left(\mathrm{CH}_{3}\right)_{3}$ contact and its possible implications have not been discussed. See: Gemel, C.; LaPensée, A.; Mauthner, K.; Mereiter, K.; Schmid, R.; Kirchner, K. The Substitution Chemistry of RuCp* (temeda)Cl. Monatsh. Chem. 1997, 128, 1189-1199.

(45) Direct contacts between $-\mathrm{Cl}$ and the $\mathrm{Si}$ atom were observed in $\sigma$-silane complexes such as $\left[\mathrm{Cp} * \mathrm{RuCl}\left(\mathrm{R}_{3} \mathrm{P}\right)\left(\sigma-\mathrm{H}-\mathrm{SiCl}_{3}\right)\right]$. See: Gutsulyak, D. V.; Churakov, A. V.; Kuzmina, L. G.; Howard, J. A.
K.; Nikonov, G. I. Steric and Electronic Effects in Half-Sandwich Ruthenium Silane $\sigma$-Complexes with $\mathrm{Si}-\mathrm{H}$ and $\mathrm{Si}-\mathrm{Cl}$ Interligand Interactions. Organometallics 2009, 28, 2655-2657.

(46) (a) Rahm, M.; Hoffmann, R.; Ashcroft, N. W. Atomic and Ionic Radii of Elements 1-96. Chem. - Eur. J. 2016, 22, 14625-14632. (b) Bondi, A. van der Waals Volumes and Radii. J. Phys. Chem. 1964, $68,441-451$.

(47) Rummelt, S. M.; Radkowski, K.; Rosca, D.-A.; Fürstner, A. Interligand Interactions Dictate the Regioselectivity of trans-Hydrometalations and Related Reactions Catalyzed by $[\mathrm{Cp} * \mathrm{RuCl}]$. Hydrogen Bonding to a Chloride Ligand as a Steering Principle in Catalysis. J. Am. Chem. Soc. 2015, 137, 5506-5519.

(48) Rosca, D.-A.; Radkowski, K.; Wolf, L. M.; Wagh, M.; Goddard, R.; Thiel, W.; Fürstner, A. Ruthenium-Catalyzed Alkyne transHydrometalation: Mechanistic Insights and Preparative Implications. J. Am. Chem. Soc. 2017, 139, 2443-2455.

(49) Le Paih, J.; Vovard-Le Bray, C.; Dérien, S.; Dixneuf, P. H. Ruthenium-Catalyzed Synthesis of Functional Conjugated Dienes via Addition of Two Carbene Units to Alkynes. J. Am. Chem. Soc. 2010, 132, 7391-7397.

(50) Dérien, S.; Jan, D.; Dixneuf, P. H. Ruthenium-Catalyzed Coupling of Allyl Alcohol with Alkynes: A New Route to $\gamma, \hat{o}-$ Unsaturated Acetals and Aldehydes. Tetrahedron 1996, 52, 55115524.

(51) For the interpretation of this result in terms of interligand interactions, see ref 47 .

(52) For related tactics to study intermediates derived from Grubbs catalysts, see: (a) Tallarico, J. A.; Bonitatebus, P. J.; Snapper, M. L. Ring-Opening Metathesis. A Ruthenium Catalyst Caught in the Act. J. Am. Chem. Soc. 1997, 119, 7157-7158. (b) Anderson, D. R.; Hickstein, D. D.; O’Leary, D. J.; Grubbs, R. H. Model Compounds of Ruthenium-Alkene Intermediates in Olefin Metathesis Reactions. J. Am. Chem. Soc. 2006, 128, 8386-8387. For an unconstrained example, see: (c) van der Eide, E. F.; Romero, P. E.; Piers, W. E. Generation and Spectroscopic Characterization of Ruthenacyclobutane and Ruthenium Olefin Carbene Intermediates Relevant to Ring Closing Metathesis Catalysis. J. Am. Chem. Soc. 2008, 130, 44854491.

(53) Upon standing in solution, carbene 41 slowly converts into an isomeric alkene via a 1,2- $\mathrm{H}$ shift from the less hindered methylene group; cf. the Supporting Information.

(54) Crabtree, R. H. The Organometallic Chemistry of the Transition Metals, 4th ed.; Wiley: Hoboken, NJ, 2005.

(55) A dynamic behavior at ambient temperature is manifested in a line broadening of one of the $\mathrm{H}$ atoms of the methylene group formed by gem-hydrogenation, which in turn implies that the side chain is dangling; even though this motion is frozen out at $-20{ }^{\circ} \mathrm{C}$, the missing NOE signal between the -OMe group and the methyl substituents of the $\mathrm{Cp}^{*}$ ring speak against any interaction between the ether and the metal center, as do the high-field resonances of the bound alkene that persist over the entire temperature range.

(56) For complexes of this type characterized by X-ray crystallography, see ref 8 and the following: (a) Gagné, M. R.; Grubbs, R. H.; Feldman, J.; Ziller, J. W. Catalytic Activity of a WellDefined Binuclear Ruthenium Alkylidene Complex. Organometallics 1992, 11, 3933-3935. (b) Risse, J.; Dutta, B.; Solari, E.; Scopelleti, R.; Severin, K. Contribnutions to the Chemistry of the Cyclopentadienyl Complex $\left[\mathrm{Cp} \wedge \mathrm{RuCl}_{2}\right]_{2}$ ("Cp-roof" $=\eta^{5}-1-$ Methoxy-2,4tert-butyl-3-neopentyl-cyclopentadienyl). Z. Anorg. Allg. Chem. 2014, $640,1322-1329$

(57) For stability scales that show the effect of $\pi$-donor substituents on free carbenes, see: (a) Mueller, P. H.; Rondan, N. G.; Houk, K. N.; Harrison, J. F.; Hooper, D.; Willen, B. H.; Liebmann, J. F. Carbene Singlet-Triplet Gaps. Linear Correlations with Substituent $\pi$ Donation. J. Am. Chem. Soc. 1981, 103, 5049-5052. (b) Mieusset, J.-L.; Brinker, U. H. The Carbene Reactivirty Surface: A Classification. J. Org. Chem. 2008, 73, 1553-1558.

(58) For a recent case study and a compilation of pertinent literature, see: Tskhovrebov, A. G.; Lingnau, J. B.; Fürstner, A. Gold 
Difluorocarbenoid Complexes: Spectroscopic and Chemical Profiling. Angew. Chem., Int. Ed. 2019, 58, 8834-8838.

(59) In this context, it is relevant to note that Grubbs-type catalysts with a heteroatom at the carbene center are readily formed but have (multiple) low-energy decomposition pathways. See: Louie, J.; Grubbs, R. H. Metathesis of Electron Rich Olefins: Structure and Reactivity of Electron-rich Carbene Complexes. Organometallics 2002, 21, 2153-2164.

(60) Macnaughtan, M. L.; Johnson, M. J. A.; Kampf, J. W. Olefin Metathesis Reactions with Vinyl Halides: Formation, Observation, Interception and Fate of the Ruthenium-Monohalomethylidene Moiety. J. Am. Chem. Soc. 2007, 129, 7708-7709.

(61) For an instructive case study, see: Schnatter, W. F. K.; Rogers, D. W.; Zavitsas, A. A. Electrophilic Addition to Alkenes: The Relation between Reactivity and Enthalpy of Hydrogenation: Regioselectivity is Determined by the Stability of the Two Conceivable Products. Chem. - Eur. J. 2015, 21, 10348-10361.

(62) Electrophilic carbenes can react with an alkene to generate reactive intermediates of largely carbenium ion character; see ref 57 and the following: Brookhart, M.; Kegley, S. E.; Husk, G. R. Transfer of Ethylidene from $\eta^{6}-\mathrm{C}_{5} \mathrm{H}_{5}(\mathrm{CO})_{2} \mathrm{Fe}=\mathrm{CHCH}_{3}{ }^{+}$to Para-Substituted Styrenes. Loss of Stereochemistry about the $\mathrm{C}_{\alpha}-\mathrm{C}_{\beta}$ Double Bond of cis- $\beta$-Deuterio- $p$-methoxystyrene. Organometallics 1984, 3, 650-652.

(63) The mass balance of the stoichiometic reaction of alkenyl chloride $1 \mathrm{~g}$ is poor, but no other discrete product could be isolated from the crude reaction mixture.

(64) (a) Korkowski, P. F.; Hoye, T. R.; Rydberg, D. B. Fischer Carbene Mediated Conversion of Enynes to Bi- and Tricyclic Cyclopropane-Containing Carbon Skeletons. J. Am. Chem. Soc. 1988, 110, 2676-2678. (b) Hoye, T. R.; Suriano, J. A. Reactions of Pentacarbonyl(1-methoxyethylidene)-molybdenum and - tungsten with $\alpha, \omega$-Enynes: Comparison with the Chromium Analogue and Resulting Mechanistic Ramifications. Organometallics 1992, 11, 2044-2050. (c) Mori, M.; Watanuki, S. New Syntheses of Pyrrolidine Derivatives via the Chromacyclobutanes Generated from Enynes and Fischer Carbene Complexes. J. Chem. Soc., Chem. Commun. 1992, 1082-1083. (d) Casey, C. P.; Hornung, N. L.; Kosar, W. P. Intramolecular Cyclopropanation and Olefin Metathesis Reactions of $(\mathrm{CO})_{5} \mathrm{~W}=\mathrm{C}\left(\mathrm{OCH}_{2} \mathrm{CH}_{2} \mathrm{CH}=\mathrm{CHOCH}_{3}\right) \mathrm{C}_{6} \mathrm{H}_{4}-p-\mathrm{CH}_{3}$. J. Am. Chem. Soc. 1987, 109, 4908-4916. (e) Barluenga, J.; Andina, F.; Aznar, F.; Valdés, C. New Cascade Processes on Group 6 Fischer-Type Carbene Complexes: Cyclopropanation and Metathesis Reactions. Org. Lett. 2007, 9, 4143-4146.

(65) Catalytic manifestations of such divergent reactivity are exceedingly rare; cf. ref 17 . We know of only one example in which a classical Grubbs catalyst engaged an enyne into metathesis/ cyclopropanation: (a) Peppers, B. P.; Diver, S. T. Tandem Cyclopropanation/Ring-Closing Metathesis of Dienynes. J. Am. Chem. Soc. 2004, 126, 9524-9525. Furthermore, remotely related examples are known in which a Grubbs catalyst is used to decompose a diazo derivative to give a new carbene complex that then leads to cyclopropanation/metathesis cascades. See: (b) Alcaide, B.; Almendros, P.; Luna, A. Chem. Rev. 2009, 109, 3817-3858.

(66) Noels, A. F.; Demonceau, A.; Carlier, E.; Hubert, A. J.; Márquez-Silva, R.-L.; Sánchez-Delgado, R. A. Competitive Cyclopropanation and Cross-metathesis Reactions of Alkenes Catalysed by Diruthenium Tetrakis Carboxylates. J. Chem. Soc., Chem. Commun. 1988, 783-784.

(67) Neese, F. The ORCA Program System. Wiley Interdiscip. Rev.: Comput. Mol. Sci. 2012, 2, 73-78.

(68) Riplinger, C.; Pinski, P.; Becker, U.; Valeev, E. F.; Neese, F. Sparse Maps - A Systematic Infrastructure for Reduced-scaling Electronic Structure Methods. II. Linear Scaling Domain Based Pair Natural Orbital Coupled Cluster Theory. J. Chem. Phys. 2016, 144, 024109.

(69) Stephens, P. J.; Devlin, F. J.; Chabalowski, C. F.; Frisch, M. J. $A b$ Initio Calculation of Vibrational Absorption and Circular Dichroism Spectra Using Density Functional Force Fields. J. Phys. Chem. 1994, 98, 11623-11627.
(70) Grimme, S.; Ehrlich, S.; Goerigk, L. Effect of the Damping Function in Dispersion Corrected Density Functional Theory. J. Comput. Chem. 2011, 32, 1456-1465.

(71) Riplinger, C.; Sandhoefer, B.; Hansen, A.; Neese, F. Natural triple excitations in local coupled cluster calculations with pair natural orbitals. J. Chem. Phys. 2013, 139, 134101.

(72) Barone, V.; Cossi, M. Quantum Calculation of Molecular Energies and Energy Gradients in Solution by a Conductor Solvent Model. J. Phys. Chem. A 1998, 102, 1995-2001.

(73) With regard to the solvation correction, SMD and C-PCM solvation schemes provided essentially the same results for all relevant stationary points on the potential energy surface; for details, see the Supporting Information.

(74) Yepes, D.; Neese, F.; List, B.; Bistoni, G. Unveiling the Delicate Balance of Steric and Dispersion Interactions in Organocatalysis Using High-Level Computational Methods. J. Am. Chem. Soc. 2020, $142,3613-3625$.

(75) (a) Bannwarth, C.; Ehlert, S.; Grimme, S. GFN2-xTB - An Accurate and Broadly Parametrized Self-Consistent Tight-Binding Quantum Chemical Method with Multipole Electrostatics and Density-Dependent Dispersion Corrections. J. Chem. Theory Comput. 2019, 15, 1652-1671. (b) Grimme, S. Exploration of Chemical Compound, Conformer, and Reaction Space with Meta-Dynamics Simulations Based on Tight-Binding Quantum Chemical Calculations. J. Chem. Theory Comput. 2019, 15, 2847-2862.

(76) Even for metallacycles derived from classical Grubbs carbenes the surrounding energy barriers can vanish, especially in exergonic reactions. See: Adlhart, C.; Chen, P. Mechanism and Activity of Ruthenium Olefin Metathesis Catalysts: The Role of Ligands and Substrates from a Theoretical Perspective. J. Am. Chem. Soc. 2004, $126,3496-3510$.

(77) Similar agostic interactions have previously been proposed in cyclopropanation reactions of piano-stool ruthenium carbenes generated with the aid of diazoalkanes; see ref $16 \mathrm{a}$.

(78) For the sake of completeness we add that Figure 3 must not be misinterpreted in that cyclopropane formation is also favored on thermodynamic grounds. Note that the metathesis pathway is not yet closed at the stage where product $\mathbf{C}$ and the secondary carbene $\left[\mathrm{Cp} * \mathrm{Ru}(\mathrm{Cl})\left(=\mathrm{CH}_{2}\right)\right]$ are formed; rather, the latter must be reconverted into the propagating species by subsequent hydrogenation, which is known to be a highly exothermic process (cf. refs 2 and 3).

(79) The higher barrier for substrate 1a carrying two methyl substituents at the olefin is tentatively ascribed to steric hindrance in the reductive elimination step.

(80) The barrier $\mathrm{TS}_{\mathrm{DE}}$ for reductive elimination of the ordinary metallacycle $\mathbf{D}$ with formation of the cyclopropane is also very responsive to the changes and can even be higher than that of $\mathbf{T S}_{\mathrm{AD}}$ (see Figure 4); in no case investigated, however, does $\mathbf{T S}_{\mathrm{AD}}$ ultimately determine the reaction outcome.

(81) Gordon, C. P.; Yamamoto, K.; Liao, W.-C.; Allouche, F.; Andersen, R. A.; Copéret, C.; Raynaud, C.; Eisenstein, O. Metathesis Activity Encoded in the Metallacyclobutane Carbon-13 NMR Shift Tensors. ACS Cent. Sci. 2017, 3, 759-768.

(82) (a) Remya, P. R.; Suresh, C. H. Hypercoordinate $\beta$-Carbon in Grubbs and Schrock Olefin Metathesis Metallacycles. Dalton Trans. 2015, 44, 17660-17672. (b) Suresh, C. H. Nature of $\alpha, \beta$-CCC Agostic Bonding in Metallacyclobutanes. J. Organomet. Chem. 2006, 691, 5366-5374.

(83) Etienne, M.; Weller, A. S. Intramolcular C-C Agostic Complexes: C-C Sigma Interactions by Another Name. Chem. Soc. Rev. 2014, 43, 242-259.

(84) (a) Evans, M. G.; Polanyi, M. Inertia and Driving Force of Chemical Reactions. Trans. Faraday Soc. 1938, 34, 11-24. (b) Hammond, G. S. A Correlation of Reaction Rates. J. Am. Chem. Soc. 1955, 77, 334-338. 